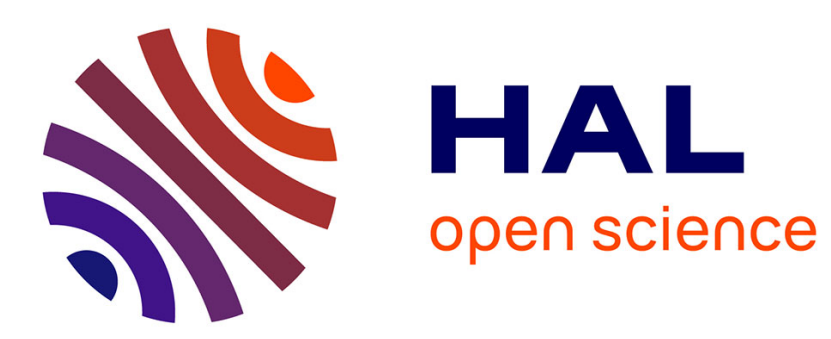

\title{
Harder, Better, Faster... Yet Stronger? Working Conditions and Self-Declaration of Chronic Diseases
} Éric Defebvre

\section{To cite this version:}

Éric Defebvre. Harder, Better, Faster... Yet Stronger? Working Conditions and Self-Declaration of Chronic Diseases. Health Economics, 2018, 27 (3), pp.e59-e76. 10.1002/hec.3619 . hal-02070311

\section{HAL Id: hal-02070311 https://hal.science/hal-02070311}

Submitted on 17 Mar 2019

HAL is a multi-disciplinary open access archive for the deposit and dissemination of scientific research documents, whether they are published or not. The documents may come from teaching and research institutions in France or abroad, or from public or private research centers.
L'archive ouverte pluridisciplinaire HAL, est destinée au dépôt et à la diffusion de documents scientifiques de niveau recherche, publiés ou non, émanant des établissements d'enseignement et de recherche français ou étrangers, des laboratoires publics ou privés. 


\title{
HARDER, BETTER, FASTER... YET STRONGER? WORKING CONDITIONS AND SELF-DECLARATION OF CHRONIC DISEASES
}

\author{
ÉRIC DEFEBVRE ${ }^{\mathrm{a}}$ \\ ${ }^{a}$ Érudite, Paris-Est Créteil University, 61 avenue du Général de Gaulle, 94010 Créteil, France and Tepp FR $n^{\circ} 3435$-CNRS \\ Mail: eric.defebvre@univ-paris-est.fr.Phone: +33651775786
}

Body text word count: 7086

Table count: 11

Figure count: 4

\begin{abstract}
The role played by working conditions in worker health status has been widely acknowledged in the literature in general but has received less attention in economics, due to the inherent statistical biases and lack of data available to determine the role of simultaneous and chronic exposures. This study aims to estimate the causal impact of detrimental working conditions on the self-declaration of chronic diseases in France. Using a rebuilt retrospective lifelong panel and defining indicators for physical and psychosocial strains, I implement a mixed econometric strategy that relies on difference-in-differences and matching methods to take into account for selection biases as well as unobserved heterogeneity. For men and women, I find deleterious effects of both types of working conditions on the declaration of chronic diseases after exposure, with varying patterns of impacts according to the nature and magnitude of the strains. These results provide insights into the debate on legal retirement age postponement and justify not only policies being enacted early in individuals' careers in order to prevent subsequent mid-career health repercussions, but also schemes that are more focused on psychosocial risk factors.
\end{abstract}

Key words: Working conditions; Chronic diseases; Difference in differences; Matching

JEL classifications: $\mathrm{J} 81 ; \mathrm{I} 14 ; \mathrm{C} 32$

Conflict of interest: none. 


\section{INTRODUCTION}

In a context of changing and increasing work pressures (Askenazy and Caroli, 2010), the question of working conditions has become even more acute. Notably, a law implemented in 2015 in France fits into this logic and either offers access to training programs in order to change jobs or gives the most exposed workers an opportunity to retire earlier.

The relationship between employment, work and health status has received considerable attention in the scientific community, especially in fields such as epidemiology, sociology, management, psychology and ergonomics. From a theoretical standpoint in economics, the differences in wages between equally productive individuals can be explained by differences in the difficulty of work-related tasks, meaning workers with poorer working conditions are paid more than others in a perfectly competitive environment (Rosen, 1974). In this framework, it is possible to imagine that health capital and wealth stock are substitutable, hence workers may use their health in exchange for income (Muurinen and Le Grand, 1985). From an empirical point of view, the question of working conditions and their potential effects on health status becomes crucial in a general context of legal retirement age postponement being linked to increasing life expectancy and the need to maintain the financial equilibrium of the pension system. Prolonged exposures throughout one's whole career are indeed likely to prevent the most vulnerable from reaching further retirement ages, a fortiori in good health condition. However, this research area has received less attention because of important endogeneity problems such as reverse causality, endogenous selection and unobserved heterogeneity (Barnay, 2016) as well as the difficulty in fully embracing the diversity and magnitude of exposures. Nevertheless, a large majority of the studies agree that there is a deleterious effect on health status from detrimental working conditions.

In this paper, I examine the role of physical and psychosocial working conditions as well as their interactions when declaring chronic diseases. I expand on the aforementioned literature 
by two means. First, I rely on a sample of around 6,700 French male and female workers who participated in the French Health and Professional Route survey (Santé et Itinéraire Professionnel-Sip), for whom it is possible to use retrospective panel data for reconstructing their entire career from their entry into the labour market to the date of the survey. This allows me to resolve the inherent endogeneity in the relationship caused by selection biases and unobserved heterogeneity using a difference-in-differences methodology combined with matching methods. My second contribution arises from being able to establish and analyze the role of progressive and differentiated types of exposures and account for potentially delayed effects on health status. I believe such a work does not exist in the literature and that it provides useful insights for policy-making, particularly in regard to the importance of considering potentially varying degrees of exposures as well as the physical and psychosocial risk factors in a career-long perspective.

The paper first presents an overview of the economic literature (Section 1), the general framework of this study (Section 2), the data (Section 3) and empirical methodology (Section 4). Then, the results are presented, along with robustness checks and a discussion (Section 5, Section 6 and Section 7).

\section{Literature}

\subsection{Global effect of work strain on health status}

The economic literature generally agrees on a deleterious mean effect of work strain on workers' health capital (Barnay, 2016; Fletcher et al., 2011). The numerous existing indicators used to assess this role usually classify the strains into two main categories: those related to physical or environmental burdens and psychosocial risk factors.

Having a physically demanding job is known to impact self-rated health (Case and Deaton, 2003; Choo and Denny, 2006; Debrand and Lengagne, 2008; Ose, 2005; Robone et al., 2011). Notably, Case and Deaton (2003) use multiple cross-sectional data to find that manual work 
significantly deteriorates self-assessed health status. This result is robust to the inclusion of classical socio-demographic characteristics and it varies according to the levels of pay and skills involved. This was later confirmed by Choo and Denny (2006), who also used crosssectional data. Using panel data, Ose (2005) finds that, after taking into account possible compensations, a heavy workload causes ill health and greater absenteeism. Based also on panel data, Robone et al. (2011) focus on the role of the workplace, atypical work hours (including night work) and general job satisfaction to find an influence on both self-assessed health and well-being. Job satisfaction is confirmed to have a positive effect on objective and subjective health status measures, based on panel data used by Fischer and Sousa-Poza (2009). The work environment is also found to have an influence on workers' health status. In a study on U.S. workers, the impact of facing detrimental environmental working conditions (weather, extreme temperatures or moisture) is found to specifically impact young worker's self-rated health status (Fletcher et al., 2011). Datta Gupta and Kristensen (2008) use longitudinal data and cross-country comparisons to show that a favourable work environment and high job security lead to better health conditions.

Psychosocial risk factors have been studied more recently in the empirical literature (Askenazy and Caroli, 2010; Cohidon et al., 2010; Cottini and Lucifora, 2013; Kuper and Marmot, 2003; Laaksonen et al., 2006), even though their initial formulation in the psychological field is older (Johnson et al., 1989; Karasek, 1979; Theorell and Karasek, 1996). Individuals in a situation of job strain are found to suffer more frequently from coronary heart diseases (Kuper and Marmot, 2003). Johnson et al. (1989) demonstrated that social isolation combined with job strain correlates with cardiovascular diseases (iso-strain situation). Mental health is also potentially impaired by such exposures. Laaksonen et al. (2006) show that stress at work, job demands, weak decision latitude, lack of fairness and support are related to poorer health status. Bildt and Michélsen (2002) show that being exposed to various work stressors such as weak social support and lack of pride at work may 
be related to a worse mental health condition, while Cohidon et al. (2010) stress the role of being in contact with the public. Part of the literature also focuses on the role of rewards at work and how it might help in coping with demanding jobs (Siegrist, 1996). Notably, de Jonge et al. (2000) use a large-scale cross-sectional dataset to find effects of job demands and effort-reward imbalance on workers' well-being. Cottini and Lucifora (2013) use three waves of European data on 15 countries and find that job quality (in particular job demands) affects mental health.

\subsection{The role of simultaneous and chronic exposures}

Even though the economic literature on the topic of exposure to detrimental working conditions is scarce in regard to both simultaneous exposures (multiple exposures at once) and cumulative exposures (length of exposure to given strains), other fields such as epidemiology have demonstrated their importance in terms of work strains and their impact on health status (Michie and Williams, 2003). By its very nature, the literature that focuses on Karasek's and Siegrist's models tend to study the results of combined exposures to several, simultaneous work stressors (job strain and iso-strain). de Jonge et al. (2000) show the independent and cumulative effects of both types of models. On the matter of cumulative exposures, Amick et al. (1998) demonstrate with longitudinal data that chronic exposure to low job control is related to higher mortality in women. The study of Fletcher et al. (2011) uses panel data and analyses the role of cumulative physical and environmental exposures over five years (from 1993 to 1997) while controlling for initial health status and health-related selection. This study is likely to be the closest paper in the literature to the present study. They aggregate several physical and environmental working conditions indicators and create composite scores, which they then sum over five years. They find clear impacts of these indicators on both men and women, with variations depending on demographic subgroups. I expand on this particular study notably by considering exposures to both physical and psychosocial risk factors as well as by taking into account exposures that occur throughout the whole career 
(one can easily imagine larger health effects in cases of longer exposures). I also include the possibility of accounting for simultaneous exposures.

\subsection{Biases}

More often than not, the literature's assessment of the health-related consequences of exposures to working conditions is plagued with several methodological biases that can lead to potentially misleading results. First, the choice of a job is unlikely a random experience (Cottini and Lucifora, 2013), resulting in contradictory assumptions. In particular, healthier individuals may tend to prefer (self-selection) or to be preferred (discrimination) for more demanding jobs (Barnay et al., 2015). In this case, the estimations are likely to be biased downwards because of both healthier and more exposed individuals to demanding jobs being overrepresented in the sample (inducing a Healthy Worker Effect - Haan and Myck, 2009). Second, it is also reasonable to assume that workers with lesser health capital may have fewer opportunities in the labour market and thus be restricted to the toughest jobs, in which case an upward bias may result. Therefore, unobserved individual and temporal heterogeneities that are unaccounted for may also result in biased estimations (Lindeboom and Kerkhofs, 2009). Individual preferences and risk aversion behaviours as well as shocks, crises or other timerelated events can cast doubt on the exogeneity hypothesis of working conditions (Bassanini and Caroli, 2015).

Due to a lack of panel data that includes detailed information on both work and health status over longer periods, few papers have actually succeeded in handling these biases. Notably, Cottini and Lucifora (2013) implemented an instrumental variable strategy on repeated crosssectional data while relying on variations across countries in terms of workplace health and safety regulation, doing so in order to identify the causal effect of detrimental working conditions on mental health. In most cases, the difficulty in finding accurate and reliable instruments for working conditions leads to the question of selection, and unobserved 
heterogeneity is either treated differently or avoided altogether when working on crosssectional data.

\section{General framework}

The main objective of this study is to assess the role of varying levels of exposure to detrimental working conditions in declaring chronic diseases. To do so, I rely on a differencein-differences framework which considers a chronic diseases baseline period, i.e., the initial number of chronic diseases before all possible exposures to work strains, and a follow-up period after a certain degree of exposure has been sustained (which is called the treatment).

\section{[Figure 1: Configuration of working conditions and chronic diseases periods]}

Thus, a total of four chronic disease periods are defined (Figure 1). The baseline period consists of the two years before labour market entry and represents an indicator for the initial exogenous health capital. Following labour market entry and potential subsequent exposures to work strains, three two-year chronic disease follow-up periods are reconstructed, representing short- to mid-term post-treatment health conditions.

After labour market entry, employment and working conditions are observed and the treatment may take place. To allow for more homogeneity in terms of exposure and treatment dates, as well as to ensure that exposure periods cannot be very much separated from each other, I observe working conditions within a dedicated period (starting from labour market entry year). In order to be treated, one must reach the treatment threshold within this observation period. The other individuals are considered controls. Minimum durations of work are also introduced: because individuals who do not participate in the labour market are likely to be very specific in terms of labour market and health characteristics, they are at risk of not really being comparable to other workers (Llena-Nozal et al., 2004).

\section{[Table I: Thresholds description]}


Nine progressive exposure levels (denoted $t_{N}$ ) have been designed in order to assess potentially varying effects of increasing strains on declaring chronic diseases. In order to take into account the cumulative effects between strains, two types of exposure are considered (see first half of Table I): single exposure (when an individual faced only one strain at a time each year) and poly-exposure (if an individual faced two or more strains simultaneously each year). Then, the duration of exposure is accounted for by introducing varying minimum durations of exposure (thresholds). Empirically, this framework covers exposure thresholds ranging from 4 years of single exposure or 2 years of poly-exposure $\left(t_{1}\right)$ to, respectively, 20 and 10 years of exposure $\left(t_{9}\right)$, with a step of 2 years (resp. 1 year) from a threshold to another for single (resp. poly-) exposures. However, changing the treatment thresholds will, as a consequence, lead to other necessary changes in the framework, notably to the duration of the working conditions observation period and to the minimum duration at work within it (see second half of Table I). More details about the choices made for these parameters can be found in Appendix 1. Note that only thresholds $t_{5}$ to $t_{9}$ are presented in the rest of the paper (for simplification purposes), because previous thresholds reveal no significant effect on chronic diseases from exposure to detrimental working conditions.

\section{Data}

\subsection{The Santé et Itinéraire Professionnel (Sip) survey}

I use data coming from the French Health and Professional Route survey (Santé et Itinéraire Professionnel-Sip). It has been designed jointly by the statistical departments of two French ministries in charge of Health ${ }^{1}$ and Labour ${ }^{2}$. The panel is composed of two waves (2006 and 2010). Two questionnaires are proposed: the first one is administered directly by an interviewer and investigates individual characteristics, health and employment statuses. It also contains a life grid, which allows reconstructing biographies of individuals' lives: childhood,

\footnotetext{
${ }^{1}$ Directorate for Research, Studies, Assessment and Statistics (Drees) - Ministry of Health.

${ }^{2}$ Directorate for Research, Studies and Statistics (Dares) - Ministry of Labour.
} 
education, health, career and working conditions, as well as major life events. The second one is self-administered and focuses on more sensitive information such as health-related risky behaviours (weight, alcohol and tobacco consumption). Overall, more than 13,000 individuals were interviewed in 2006 and 11,000 in 2010, making this panel survey representative of the French population ${ }^{3}$.

I make specific use of the biographic dimension of the 2006 survey by reconstructing workers' career and health events yearly ${ }^{4}$ I am therefore able to know each individual's employment status, working conditions and chronic diseases every year from their childhood to the date of the survey (2006). As far as work strains are concerned, the survey provides information about ten indicators of exposure. The intensity of exposure to these work strains is also known. Individuals' health statuses are assessed by their declaration of chronic diseases, for which the onset and end dates are available.

In this study, I work with this reconstructed longitudinal retrospective dataset comprising more than 6,700 individuals, including their career and health-related data from childhood to the year of the survey. Thus, the final working sample is composed of around 3,500 men and 3,200 women, for whom complete information is available and who meet specific inclusion criteria (see Appendix 1).

\subsection{Variables of interest}

\subsubsection{Working conditions: Definition of a treatment}

Ten individual annual indicators are used to assess the exposure to detrimental work strains and I regroup them into three relevant categories. The first one represents the physical load of work and includes night work, repetitive work, physical load and exposure to toxic materials. The second one forms the psychosocial risk factors that include full skill usage, working under pressure, tensions with the public, reward, conciliation between work and family life

\footnotetext{
${ }^{3}$ For a technical note on attrition management and data calibration in the Sip survey, see De Riccardis (2012).

${ }^{4}$ It is not possible to know what happened between 2006 and 2010, making the latter wave unusable in this study.
} 
and relationships with colleagues. The third one represents the global exposure to both physical and psychosocial strains (which includes all ten working conditions indicators). For each indicator, individuals must declare if they "Always", "Often", "Sometimes" or "Never" faced it during this period: I consider one individual to be exposed if he/she "Always" or "Often" declared facing these strains.

\subsubsection{Chronic diseases}

The indicator of health status is the annual number of chronic diseases ${ }^{5}:$ a chronic disease is understood in the Sip survey to be an illness that lasts or will last for a long time, or an illness that returns regularly. Allergies such as hay fever or the flu are not considered chronic diseases. This definition is broader than the French administrative definition, and it is selfdeclarative. This indicator is available from childhood to the date of the survey (2006). Available chronic diseases include cardiovascular diseases, cancers, pulmonary problems, ENT disorders, digestive, mouth and teeth, bones and joints, endocrine, metabolic and ocular problems, nervous and mental illnesses, neurological problems, skin diseases and addictions.

\subsection{General descriptive statistics}

Table II below gives a description of the sample used in the $7^{\text {th }}$ threshold described above. I chose this specific threshold because it should give an adequate representation of the average of the studied population (as it is the middle point between presented thresholds $t_{5}$ to $t_{9}$ and because it should not differ in non-treatment-related characteristics for the most part, due to the samples used for all thresholds being the same).

The main conclusions of these descriptive statistics are, first, that the populations who are to be physically and globally treated seem to initially be in a better health condition than their respective control groups. Such a difference cannot be found in the psychosocial sample. Second, no significant effect of the physical and global treatments is observed on subsequent

\footnotetext{
${ }^{5}$ Only accidents, handicaps and chronic diseases can be reconstructed year by year in the Sip survey. To avoid mixing-up overly different types of indicators, I chose to keep only the latter.
} 
numbers of chronic diseases. This is once again the opposite for the psychosocial subsample, which displays growingly significant and negative differences in the number of chronic diseases between treated and control groups, thus revealing a potentially detrimental effect on health status from psychosocial exposures. However, because the structures of the treated and control groups are very heterogeneous in terms of observed characteristics, the differences in chronic diseases for each period between the two are likely to be unreliable. Yet, for at least the physically and globally demanding jobs, there seem to be signs of a sizeable selection effect indicating that healthier individuals prefer or are preferred for these types of occupations.

\section{[Table II: Base sample description $\left(t_{7}\right)$ ]}

\section{Empirical analysis}

\subsection{Econometric strategy}

The general framework of the difference-in-differences methodology is given by Equation 1 (Angrist and Pischke, 2009). The left-hand side of Equation (1) gives the observed performance difference between the treated and control groups. The first right-hand side term is the average treatment effect on the treated $(A T T)$, and the far right-hand side term is the selection bias. The latter equals 0 when the potential performance without treatment $\left(Y_{0 i}\right)$ is the same whatever the group to which one belongs (independence assumption): $\left\{Y_{0 i}, Y_{1 i}\right\} \perp T_{i}$.

$$
E\left(Y_{i} \mid T_{i}=1\right)-E\left(Y_{i} \mid T_{i}=0\right)=E\left(Y_{1 i}-Y_{0 i} \mid T_{i}=1\right)+\left[E\left(Y_{0 i} \mid T_{i}=1\right)-E\left(Y_{0 i} \mid T_{i}=0\right)\right]
$$

In practical terms, the estimation of the difference-in-differences for individual $i$ and times $t-1$ (baseline) and $t+1$ (follow-up) in this study relies on the fixed-effects, 
heteroskedasticity-robust Within panel data estimator ${ }^{6}$ estimating Equation (2), which explains the mean number of chronic diseases $\left(Y_{i t}\right)$ :

$$
Y_{i t}=\beta_{0}+\beta_{1} \mathbf{1}_{(t+1)}+\beta_{2} \mathbf{1}_{\left(T_{i}=1\right)}+\beta_{3} \mathbf{1}_{(t+1)} \times \mathbf{1}_{\left(T_{i}=1\right)}+\beta_{4} C_{i t}^{\prime}+\gamma_{i}+\gamma_{t}+\varepsilon_{i t}
$$

$\mathbf{1}_{(t+1)}$ is a dummy variable taking value 1 if the period considered is $t+1 ; \mathbf{1}_{\left(T_{i}=1\right)}$ is a dummy variable for the treatment (taking value 1 when individual $i$ is part of the treated group); $\mathbf{1}_{(t+1)} \times \mathbf{1}_{\left(T_{i}=1\right)}$ (variable of interest) is a cross variable taking value 1 when individual $i$ is treated in $t+1 ; C_{i t}^{\prime}$ is a vector of covariates and $\beta_{1}, \beta_{2}, \beta_{3}$ and $\beta_{4}$ are their respective coefficients. $\gamma_{i}$ and $\gamma_{t}$, respectively, represent the individual and temporal unobserved heterogeneities and $\varepsilon_{i t}$ the error term. The main objective of a difference-indifferences framework is to get rid of both $\gamma_{i}$ and $\gamma_{t}$, as well as to account for the baseline situation $\left(y_{i, t-1}\right)$.

In order to satisfy the independence assumption, i.e., to reduce the ex-ante differences between treated and control groups as much as possible and thus to handle the selection bias existing in the sample, I perform a matching method prior to the difference-in-differences setup using pre-treatment characteristics $\left(X_{i t}^{\prime}\right)$ related to health status and employment elements, so that $\left\{Y_{0 i}, Y_{1 i}\right\} \perp T_{i} \mid X_{i t}^{\prime}$. A Coarsened Exact Matching method is implemented (CEM - Blackwell et al., 2010). The main objective of this methodology is to allow the reduction of both univariate and global imbalances between treated and control groups according to several pre-treatment covariates. This offers two main advantages compared to other matching methods: it helps in coping effectively with the curse of dimensionality and

\footnotetext{
${ }^{6}$ It is also possible to estimate such a specification using the Ordinary Least Squares estimator and group-fixed unobserved heterogeneity. The results should be relatively close (Givord, 2008), which has been tested and is the case in this study. Yet, panel data estimators appear to be the most stable because of the increased precision of the individual fixed effects in comparison to group fixed effects, and thus have been preferred here.
} 
reduces the model dependence of the results (Iacus et al., 2008). The end result is a weight variable that is then used to in the difference-in-differences specifications ${ }^{7}$.

\subsection{Matching variables and controls}

Matching pre-treatment variables are chosen so that they are relevant in terms of health status and position in the labour market, in addition to helping cope with the (self-)selection bias (individuals sustaining high levels of exposure are bound to be particularly resilient or, in contrast, particularly deprived from better opportunities in the labour market). Individuals are matched according to their: year of entry into the labour market (in order to get rid of temporal heterogeneity related to generation/conjuncture effects); gender (Devaux et al., 2008; Shmueli, 2003); education level (four levels: no education, primary or secondary, equivalent to bachelor degree and superior); health status before labour market entry (heavy health problems and handicaps) to have a better assessment of their initial health status and to cope with endogenous sorting in the labour market; and important events during childhood, aggregated into two dummy variables (on the one hand, heavy health problems of relatives, death of a relative, separation from one or more parent; on the other hand, violence suffered from relatives and violence at school or in the neighbourhood), as it is pretty clear that such childhood events may impact early outcomes in terms of health status (Case et al., 2005; Lindeboom et al., 2002). Matching the samples on such variables is bound to reduce the initial heterogeneity existing between the treated and control groups, as well as to limit the selection bias into employment and into different degrees of exposure, as part of the individuals' resilience to work strains is accounted for notably by proxy variables for their initial health capital.

After reaching the treatment, workers can still be exposed to varying levels of working conditions. This possibility of post-treatment exposures is accounted for by a control variable

\footnotetext{
${ }^{7}$ The weight value for matched individuals equals $\frac{n_{S}^{T}}{n_{S}^{C}} \times \frac{N^{C}}{N^{T}}$, with $n_{S}$ representing the sample size for respectively the treated (T) and control (C) groups in stratum $s$ and $N$ the total sample sizes for both groups. Unmatched individuals are weighted 0.
} 
in the difference-in-differences models (taking the value 0 at baseline and 1, 2 or 3 depending on if the individual has been exposed, respectively, hardly, a little or a lot to detrimental work strains during this post-treatment period) ${ }^{8}$. Health habits are also controlled for in the difference-in-differences models by adding a variable indicating if individuals, at any given time, are daily smokers or not. The idea behind this is that health-related behaviours (such as tobacco and alcohol consumption, being overweight and other health habits) are bound to be correlated with each other as well as with exposures to work strains and with the declaration of chronic diseases, all of which induce biased estimates when unaccounted for. This variable takes the value 0 when an individual is not a daily smoker and the value 1 if he/she is in either the baseline or follow-up periods.

\subsection{Matched descriptive statistics}

The naive results (descriptive statistics presented in Section 3.3 and unmatched difference-indifferences results available upon request) tend to confirm the possibility of a (self-)selection bias in the sample, suggesting that people are likely to choose their job while considering their own initial health status; in any case, the results justify an approach that takes into account this possibility. In order to minimize this selection process, a matching method is used prior to the difference-in-differences models.

Table III gives a description of the same sample used in $t_{7}$, which was presented earlier (for comparison purposes), after CEM matching. The matching method succeeds in reducing the observed structural heterogeneity between the treated and control groups for every single pretreatment covariate. Residual heterogeneity still exists, namely for the year of entry into the labour market and age, but it is shown to be minor and, in any case, statistically nonsignificant (difference of less than a month in terms of labour market entry year and of approximately a quarter for age). It is also interesting to note that initial health status

\footnotetext{
${ }^{8}$ Nevertheless, including post-treatment variables in the models may be risky, as such variables are endogenous (exposure levels after the treatment appear as a function of the treatment itself). To account for this possibility, I also estimated the models without including variables for post-treatment exposures. The results, very similar to the main results presented in Section 5, are given in Table VII (Appendix 2).
} 
differences are also greatly reduced and that larger negative follow-up differences between treated and control groups can now be observed, making the hypothesis of a detrimental impact of working conditions on health status more credible.

\section{[Table III: Matched sample description $\left(t_{7}\right)$ ]}

\section{Main results}

The results for matched difference-in-differences models for the five thresholds are provided in Table IV, Table V and Table VI below. These results, relying on matched samples, take care of the selection biases generated by endogenous sorting in the labour market and observed heterogeneity, as well as unobserved individual fixed and time-varying heterogeneities as a result of using difference-in-differences frameworks.

[Table IV: Matched difference-in-differences results ( $t_{5}$ to $\left.t_{9}\right)$, physical treatment]

[Table V: Matched difference-in-differences results ( $t_{5}$ to $\left.t_{9}\right)$, psychosocial treatment]

[Table VI: Matched difference-in-differences results $\left(t_{5}\right.$ to $\left.t_{9}\right)$, global treatment]

It should be noted that around $90 \%$ of the initial sample is preserved after matching in physical and psychosocial samples, and that at least $80 \%$ of the sample is preserved for the global treatment (because of the higher number of treated). Matching the samples on pretreatment variables consistently succeeds in reducing initial health status gaps between treated and control groups, to the point where none of them are still present in the matched results.

It appears that men are clearly more exposed to detrimental working conditions than women, especially for physically demanding jobs (with an average of 20 percentage points $(p p)$ more in men than in women), but also to a lesser extent for psychosocial risk factors $(+3 p p$ in men). In comparison to women, the gender gap regarding all working conditions (global treatment) is approximately $+16 p p$ in men. A clear impact of exposures to work strains on the declaration of chronic diseases can be observed in the difference-in-differences (columns 
5 and 6). Treated workers indeed seem to suffer from a quicker degradation trend in their health status than their respective control groups. This trend exists between levels of exposure (thresholds), but it is also suggested by the evolution of the number of chronic diseases by health status observation period, even though these differences in means are unlikely to be statistically significant. This main result holds for all treatment types and for both genders, and it tends to demonstrate possible long-term effects of exposures rather than only short-term consequences.

In the physical sample, the first significant consequences in terms of health status degradation can be seen in women, starting from $t_{5}$ (i.e., after 12 years of single exposure or 6 years of simultaneous exposures), while this is the case much later in men, at $t_{8}$ (resp. after at least 18 or 9 years of exposure). Between $t_{5}$ and $t_{9}$, the differences between treated and control groups in the mean number of chronic diseases in women increase from .100 to .249, while in men the differences between $t_{8}$ and $t_{9}$ range from .076 to .120 . In order to have an idea of the meaning of these differences, it is possible to compare them to the mean number of chronic diseases in the treated population after the treatment occurred, given in column 7 . In physically exposed women (resp. men), exposures to work strains may account for $20 \%$ to $25 \%$ of their mean number of chronic diseases (resp. a little more than 10\%). Psychosocial strains have a more homogenous initial impact on the declaration of chronic diseases, with sizeable health status consequences happening at $t_{6}$ in men (resp. 14 or 7 years of exposure) and $t_{7}$ in women (resp. 16 or 8 years of exposure). The difference in women (resp. in men) goes from .156 in $t_{7}\left(.080\right.$ in $\left.t_{6}\right)$ to .233 in $t_{9}\left(.143\right.$ in $\left.t_{9}\right)$. Thus, in psychosocially exposed women (resp. men), approximately $21 \%$ (resp. 17\%) of chronic diseases in the treated population can be explained by psychosocial strains. For the global treatment, effects of exposures start at $t_{7}$ in women (resp. $t_{8}$ in men) and go from .148 to .209 (resp. .100 to .136 in men). According to the results for this global type of exposure, $20 \%$ (resp. $10 \%$ to $15 \%$ ) of exposed women's (resp. men's) chronic diseases come from combined physical and 
psychosocial job strains. The effects of the global treatment appear weaker in terms of onset and intensity, which is most likely due to the fact that the exposure thresholds are easier to reach because of the greater number of working condition indicators considered. Nevertheless, even though women are less exposed than men to work strains, it seems that their health status is more impacted by them.

\section{Robustness checks}

\subsection{Common trend assumption}

In order to ensure that the results obtained using a difference-in-differences framework are robust, one needs to assess whether the treated and control groups share a common trend in terms of the number of chronic diseases before all possible exposures to detrimental working conditions, i.e., before labour market entry.

Figure 2, Figure 3 and Figure 4 (Appendix 3), respectively, present the chronic disease trends for the treated and control groups in the matched physical, psychosocial and global samples for $t_{7}$. The first panel represents the baseline period and stops at the mean year of labour market entry for this sample. From all three graphs, one can see that both treated and control groups share the same trend in terms of rises in chronic diseases. This is no longer the case after labour market entry. The common trend hypothesis seems to therefore be corroborated. It should be noted that the test results on unmatched samples (available upon request) are rather close, but they are not as convincing.

\subsection{Model dependency}

I also test whether the results obtained using matched difference-in-differences could be obtained more easily by relying only on a matching method. Yet because CEM is not in itself an estimation method, I set up a simple, heteroskedasticity-robust specification that was estimated using Ordinary Least Squares on matched data with the same control variables 
(specification 3), followed by a comparison of the results with those obtained through difference-in-differences using specification 2 (Table VIII, Appendix 4).

$$
y_{i}=\beta_{0}+\beta_{1} \mathbf{1}_{\left(T_{i}=1\right)}+\beta_{2} C_{i}^{\prime}+\varepsilon_{i}
$$

The results for all three samples on $t_{7}$ indicate that, in terms of statistical significance, the detrimental impact of exposure to work strains on the number of chronic diseases is confirmed. This is not very surprising, as CEM has the particularity to reduce the model dependence of the results (Iacus et al., 2008). Yet, the amplitude of the effect is varying in OLS in comparison to difference-in-differences results. This could be explained by the fact that these simple OLS regressions neither account for initial differences in terms of health status, nor do they take into account individual and temporal unobserved heterogeneities when both these phenomena are going in opposite directions. As a consequence, difference-indifferences results are preferred here because of their increased stability and reliability.

\subsection{Single $v s$. simultaneous exposures}

I tested the relevance of the differentiation made between single and multiple exposures in the three working condition treatments, i.e., the relevance of considering that a certain number of single exposures are equivalent to half that number of poly-exposures (assumption inspired from the French legislation - Sirugue et al., 2015).

Table IX (Appendix 5) presents several results. The first two columns indicate, for $t_{7}$, the results obtained with a treatment considering 16 years of single exposures or 8 years of polyexposures (which are the main results presented in this paper). The next two columns indicate the results when considering a treatment accounting only for 16 years of single exposures. The last two columns present the results for a treatment only considering 8 years of polyexposures.

It should be noted that, logically, single exposures induce a weaker effect on the number of chronic diseases than poly-exposures. All the results still converge towards a positive and 
statistically significant effect of exposures on the declaration of chronic diseases. In addition, the differences in intensity that can be observed between individuals exposed to 16 years of single exposures and those exposed to 8 years of simultaneous exposures do not appear to be statistically significant.

\subsection{Health habits}

Even though a part of the role that health habits play in the relationship between working conditions and health (possibly generating endogeneity issues) is accounted for by controlling for the evolutions in tobacco consumption in the difference-in-differences, other behaviours (even if they are likely correlated with smoking habits) are not taken into account directly (because they cannot be reconstructed in a temporal fashion using Sip data).

Table X (Appendix 6) presents an exploratory analysis, on $t_{7}$, on the wages and risky healthrelated behaviour differences in 2006 between treated and control groups for all three treatments. In unmatched samples, important differences can be observed in terms of monthly wage, regular physical activities, alcohol, tobacco consumption and being overweight. The treated group on average earns less and does less sport but has more health-related risky behaviours than the control group. In matched samples, no statistically significant difference remains between the two groups in 2006 except for wages. This indicates that the treatment effects presented here should not pick up specific effects of health-related behaviours, except possibly those related to health investments (as the control groups are generally richer than the treated groups).

\subsection{Gender gap}

Important gender differences appear to exist in terms of effects from a certain degree of exposure to detrimental working conditions. In order to try and explain these differences, an exploratory analysis specifically on year 2006 has been conducted in Appendix 7. 
First, men and women may be employed in different activity sectors, the latter being characterized by different types of exposures to working conditions (Table XI). As expected, very large differences exist in the gender repartition as well as work strain types encountered within activity sectors. Thus, it is likely that men and women are not exposed to the same types of strains. Table XII confirms this intuition and indicates that, for at least five out of ten working conditions indicators, a statistically significant difference exists between men and women in terms of repartition into strains.

As a consequence, the explanation for this gender-gap in working conditions and health is most likely twofold. First, there might be declarative social heterogeneity between men and women. Both may not experience an objectively comparable job situation in the same way, just as they may not experience an objectively comparable health condition in the same way (Devaux et al., 2008; Shmueli, 2003). However, what could also be true is that men and women may not be exposed to the exact same typology of working conditions within a certain treatment threshold. Even though belonging to a specific treatment group ensures a quantitatively similar exposure (in terms of number of strains at a given time and in terms of lengths of exposures), it does not completely ensure that the types of strains are qualitatively equivalent, which in turn could explain part of the observed differences. Yet, this hypothesis should be partially relaxed by the use of two different treatment types (one handling physical demands and another for psychosocial risk factors).

\section{Discussion and conclusion}

In this study, I use French retrospective panel data to highlight links that physical and psychosocial working conditions - separately and combined - have with chronic diseases in exposed males and females. Workers facing gradually increasing strains in terms of duration or simultaneity of exposure are more frequently coping with rising numbers of chronic diseases. Using combined difference-in-differences and matching methods, the empirical 
strategy helps to handle both (self-)selection in the labour market based on health status and other observable characteristics as well as unobserved individual and temporal heterogeneity. Based on a career-long temporal horizon for exposures and health status observation periods, I find major differences in health conditions between treated and control groups, which are very likely the result of past exposures to work strains. To my knowledge, this is the first paper to work on both the simultaneous and cumulative effects of two distinct types of work strains and their combination with such a large temporal horizon, while acknowledging the inherent biases related to working conditions.

However, the paper suffers from some limitations. First, working with retrospective panel data and long periods of time leads to estimates being at risk of suffering from declaration biases. The individuals are rather old at the date of the survey, and their own declarations in terms of working and health conditions are therefore likely to be less precise (recall biases) or even biased (a posteriori justification or different conceptions according to different generations). Even if it is impossible to deal completely with such a bias, matching on entry year into the labour market (i.e., their generation) and on education (one of the deciding factors when it comes to memory biases) should help in reducing recall heterogeneity. Also, simple occupational information notably tends to be recalled rather accurately, even over longer periods (Berney and Blane, 1997). Second, potential biases remain in the estimations. I work on exposures happening during the first half of the professional career (i.e., to relatively young workers), at a time when individuals are more resilient to these strains. This means that the impact found in this study would most likely be higher for an equivalent exposure level if an older population were targeted. I am also unable to completely account for possible positive healthcare investments in the treated population, because if the most exposed are also better paid (hedonic price theory, Rosen, 1974), this wealth surplus could be used for relatively more health capital investments. Alternatively, the treated and control groups may have different health habits. Yet, even though wealth-type variables are endogenous, this 
hypothesis has been tested empirically with an alternative specification in the study by Fletcher et al. (2011) and they were found to be irrelevant. Also, health-related risky behaviours are at least partly accounted for by implementing a variable for tobacco consumption in the difference-in-differences models. Third, because of the method I use and the sample sizes I am working with, it is not possible to clearly analyse the potential heterogeneity in the effect of working conditions on health status across demographic and socio-economic subgroups, even though this mean effect is shown to vary (Fletcher et al., 2011; Muurinen and Le Grand, 1985). Fourth, part of the selection process into a certain level of exposure possibly remains. Considering that the sample is matched with elements of human and health capitals and because I consider only homogenous individuals present in the survey for at least 38 years (who worked at least 10 years and for whom the post-treatment exposures are controlled for), I should have rather similar individuals in terms of resilience to detrimental working conditions, i.e., with similar initial abilities to sustain a certain level of severity of exposure. So, to some extent at least, the selection into a certain level of treatment is acknowledged. Yet, it is impossible to directly match the samples on the fact that they reach a certain level of treatment or not (because it is endogenous). It should also be noted that part of the heterogeneity of the results between men and women can still be explained by declarative social heterogeneity regarding their working and health conditions as well as qualitative differences in their exposures, both elements which cannot really be accounted for using such declarative data. Finally, I use a wide definition of chronic conditions as an indicator for health status. This indicator does not allow for direct comparisons with the literature (commonly used indicators, such as self-assessed health status or activity limitations, are not available on a yearly basis). Yet, I believe that it may represent a good proxy of general health status while at the same time being less subject to volatility in declarations compared to self-assessed health (i.e., more consistent). 
These results justify more preventive measures being enacted early in individuals' careers, as it appears that major health degradations (represented by the onset of chronic conditions) tend to follow exposures that occur as early as the first half of the career. These preventive measures may first focus on workers in physically demanding jobs while also targeting workers facing psychosocial risk factors, the latter still being uncommon in public policies. These targeted schemes may benefit both society in general (through higher levels of general well-being at work and reduced healthcare expenditures later in life) and firms (more productive workers and less sick leaves). It notably appears that postponing the legal age of retirement must be backed up by such preventive measures in order to avoid detrimental adverse health effects linked to workers being exposed longer while also taking into account both types of working conditions (which is not the case in the 2015 French pension law). Today, the human and financial costs of exposures to detrimental working conditions seem undervalued in comparison to the expected implementation cost of these preventive measures. 


\section{Acknowledgements}

The author would like to especially thank Thomas Barnay (Upec Érudite) for his constant help and advice about this study. I thank Pierre Blanchard (Upec Érudite), Emmanuelle Cambois (Ined), Eve Caroli (LEDa-LEGOS, Paris-Dauphine University) and Emmanuel Duguet (Upec Érudite) for their technical help. I am thankful to Søren Rud Kristensen (Manchester Centre for Health Economics), Renaud Legal (Drees), Maarten Lindeboom (VU University Amsterdam), Luke Munford (Manchester Centre for Health Economics), Catherine Pollak (Drees) and Matthew Sutton (Manchester Centre for Health Economics) for reviewing earlier versions of the paper. I also wish to thank Patrick Domingues (Upec Érudite), Sandrine Juin (Ined, Upec Érudite), François Legendre, Dorian Verboux and Yann Videau (Upec Érudite) for their useful advice. Finally, I thank the two anonymous reviewers of the Health Economics journal. 


\section{REFERENCES}

Amick BC, Kawachi I, Coakley EH, Lerner D, Levine S, Colditz GA. 1998. Relationship of job strain and iso-strain to health status in a cohort of women in the United States. Scandinavian Journal of Work, Environment \& Health 24(1): 54-61.

Angrist JD, Pischke J-S. 2009. Mostly Harmless Econometrics: An Empiricist's Companion. Princeton University Press: Princeton.

Askenazy P, Caroli E. 2010. Innovative Work Practices, Information Technologies, and Working Conditions: Evidence for France: Working Conditions in France. Industrial Relations: A Journal of Economy and Society 49(4): 544-565.

Barnay T. 2016. Health, work and working conditions: a review of the European economic literature. The European Journal of Health Economics 17(6): 693-709.

Barnay T, Duguet E, Le Clainche C, Narcy M, Videau Y. 2015. The Impact of a Disability on Labour Market Status: A Comparison of the Public and Private Sectors. Annals of Economics and Statistics (119-120): 39.

Bassanini A, Caroli E. 2015. Is Work Bad for Health? The Role of Constraint versus Choice. Annals of Economics and Statistics (119-120): 13.

Berney LR, Blane DB. 1997. Collecting retrospective data: Accuracy of recall after 50 years judged against historical records. Social Science \& Medicine 45(10): 1519-1525.

Bildt C, Michélsen H. 2002. Gender differences in the effects from working conditions on mental health: a 4-year follow-up. International Archives of Occupational and Environmental Health 75(4): 252-258.

Blackwell M, Iacus S, King G, Porro G. 2010. cem: Coarsened Exact Matching in Stata. Available from: http://gking.harvard.edu/files/gking/files/cem-stata.pdf.

Case A, Deaton A. 2003. Broken Down by Work and Sex: How Our Health Declines. National Bureau of Economic Research: Cambridge, MA. Available from: http://www.nber.org/papers/w9821.pdf [Accessed 2 September 2016].

Case A, Fertig A, Paxson C. 2005. The lasting impact of childhood health and circumstance. Journal of Health Economics 24(2): 365-389.

Choo E, Denny M. 2006. Wearing Out - The Decline of Health. Working Paper. Available from: https://www.economics.utoronto.ca/workingPapers/tecipa-258-1.pdf.

Cohidon C, Santin G, Imbernon E, Goldberg M. 2010. Working conditions and depressive symptoms in the 2003 decennial health survey: the role of the occupational category. Social Psychiatry and Psychiatric Epidemiology 45(12): 1135-1147.

Cottini E, Lucifora C. 2013. Mental health and working conditions in Europe. ILRReview Working Paper 4(66): 958-989.

Datta Gupta N, Kristensen N. 2008. Work environment satisfaction and employee health: panel evidence from Denmark, France and Spain, 1994-2001. The European Journal of Health Economics 9(1): 51-61.

De Riccardis N. 2012. Traitements de la non-réponse et calages pour l'enquête santé et itinéraire professionnel de 2010. Drees Working Paper. Available from: http://drees.social-sante.gouv.fr/IMG/pdf/seriesource_method36.pdf.

Debrand T, Lengagne P. 2008. Working Conditions and Health of European Older Workers. Irdes Working Paper.

Devaux M, Jusot F, Sermet C, Tubeuf S. 2008. Hétérogénéité sociale de déclaration de l'état de santé et mesure des inégalités de santé. Revue française des affaires sociales 2008(1): 29-47. 
Fischer JAV, Sousa-Poza A. 2009. Does job satisfaction improve the health of workers? New evidence using panel data and objective measures of health. Health Economics 18(1): 71-89.

Fletcher JM, Sindelar JL, Yamaguchi S. 2011. Cumulative effects of job characteristics on health. Health Economics 20(5): 553-570.

Givord P. 2008. Méthodes économétriques pour l'évaluation de politiques publiques. Insee Working paper. Available from: http://www.insee.fr/fr/publications-etservices/docs_doc_travail/G2010-08.pdf.

Haan P, Myck M. 2009. Dynamics of health and labor market risks. Journal of Health Economics 28(6): 1116-1125.

Iacus SM, King G, Porro G. 2008. Matching for Causal Inference Without Balance Checking. SSRN Electronic Journal. Available from: http://www.ssrn.com/abstract=1152391 [Accessed 2 September 2016].

Johnson JV, Hall EM, Theorell T. 1989. Combined effects of job strain and social isolation on cardiovascular disease morbidity and mortality in a random sample of the Swedish male working population. Scandinavian Journal of Work, Environment \& Health 15(4): 271-279.

de Jonge J, Bosma H, Peter R, Siegrist J. 2000. Job strain, effort-reward imbalance and employee well-being: a large-scale cross-sectional study. Social Science \& Medicine 50(9): 1317-1327.

Karasek RA. 1979. Job Demands, Job Decision Latitude, and Mental Strain: Implications for Job Redesign. Administrative Science Quarterly 24(2): 285.

Kuper H, Marmot M. 2003. Job strain, job demands, decision latitude, and risk of coronary heart disease within the Whitehall II study. Journal of Epidemiology \& Community Health 57(2): 147-153.

Laaksonen M, Rahkonen O, Martikainen P, Lahelma E. 2006. Associations of psychosocial working conditions with self-rated general health and mental health among municipal employees. International Archives of Occupational and Environmental Health 79(3): 205-212.

Lindeboom M, Kerkhofs M. 2009. Health and work of the elderly: subjective health measures, reporting errors and endogeneity in the relationship between health and work. Journal of Applied Econometrics 24(6): 1024-1046.

Lindeboom M, Portrait F, van den Berg GJ. 2002. An econometric analysis of the mentalhealth effects of major events in the life of older individuals. Health Economics 11(6): 505-520.

Llena-Nozal A, Lindeboom M, Portrait F. 2004. The effect of work on mental health: does occupation matter?. Health Economics 13(10): 1045-1062.

Michie S, Williams S. 2003. Reducing work related psychological ill health and sickness absence: a systematic literature review. Occupational and Environmental Medicine 60(1): 3-9.

Muurinen J-M, Le Grand J. 1985. The economic analysis of inequalities in health. Social Science \& Medicine 20(10): 1029-1035.

Ose SO. 2005. Working conditions, compensation and absenteeisme. Journal of Health Economics 24(1): 161-188.

Robone S, Jones AM, Rice N. 2011. Contractual conditions, working conditions and their impact on health and well-being. The European Journal of Health Economics: HEPAC: Health Economics in Prevention and Care 12(5): 429-444.

Rosen S. 1974. Hedonic Prices and Implicit Markets: Product Differentiation in Pure Competition. Journal of Political Economy 82(1): 34-55. 
Shmueli A. 2003. Socio-economic and demographic variation in health and in its measures: the issue of reporting heterogeneity. Social Science \& Medicine (1982) 57(1): 125134.

Siegrist J. 1996. Adverse health effects of high-effort/low-reward conditions. Journal of Occupational Health Psychology 1(1): 27-41.

Sirugue C, Huot G, Davy De Virville M. 2015. Compte personnel de prévention de la pénibilité : propositions pour un dispositif plus simple, plus sécurisé et mieux articulé avec la prévention.

Theorell T, Karasek RA. 1996. Current issues relating to psychosocial job strain and cardiovascular disease research. Journal of Occupational Health Psychology 1(1): 926. 
Figure 1: Configuration of working conditions and chronic diseases periods

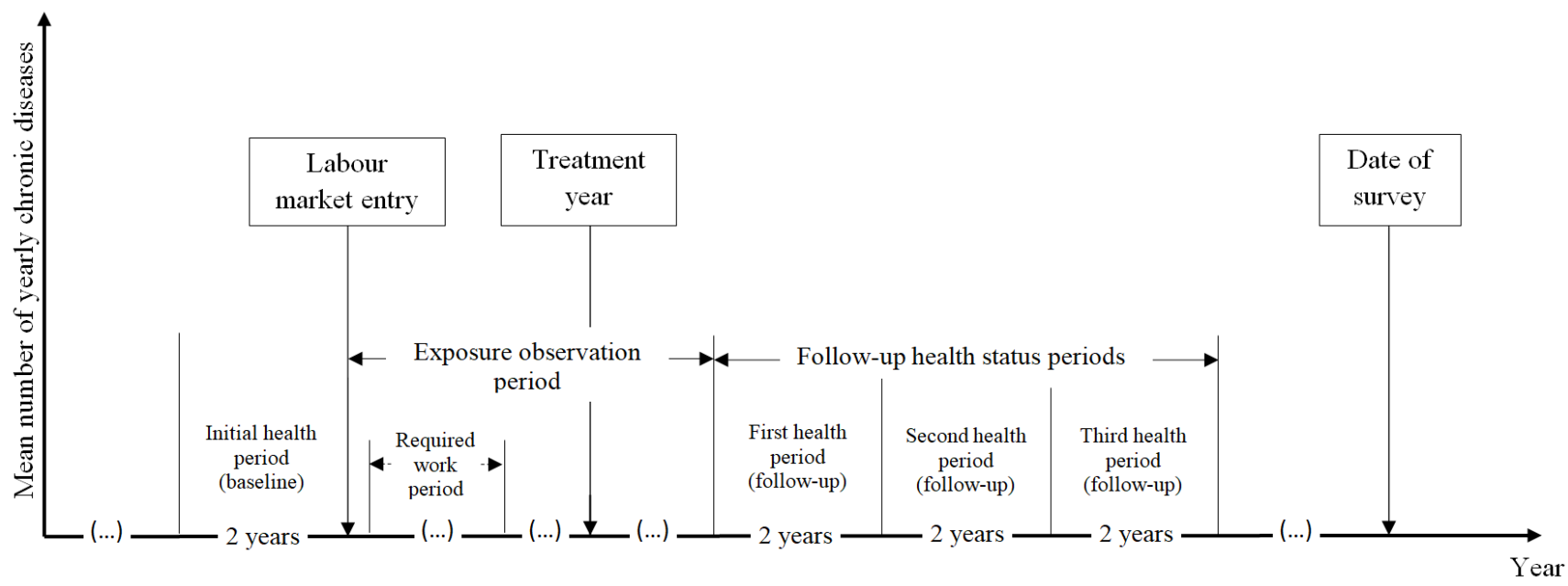

Source: Author. 
Table I: Thresholds description

\begin{tabular}{|c|c|c|c|c|c|c|c|c|c|}
\hline $\begin{array}{l}\text { Threshold } \\
\text { Parameter }\end{array}$ & $t_{1}$ & $t_{2}$ & $t_{3}$ & $t_{4}$ & $t_{5}$ & $t_{6}$ & $t_{7}$ & $t_{8}$ & $t_{9}$ \\
\hline \multicolumn{10}{|l|}{ Treatment thresholds } \\
\hline Single exposure threshold & 4 & 6 & 8 & 10 & 12 & 14 & 16 & 18 & 20 \\
\hline Poly-exposure threshold & 2 & 3 & 4 & 5 & 6 & 7 & 8 & 9 & 10 \\
\hline \multicolumn{10}{|l|}{ Periods definition } \\
\hline Working conditions observation period & 6 & 9 & 12 & 15 & 18 & 21 & 24 & 27 & 30 \\
\hline Minimum duration at work & 2 & 3 & 4 & 5 & 6 & 7 & 8 & 9 & 10 \\
\hline
\end{tabular}

Indications: in years.

Reading: For the seventh threshold $\left(t_{7}\right)$, an individual must reach 16 years of single exposure or 8 years of poly-exposure within the 24 years following labour market entry to be considered treated. Also, helshe must have worked at least 8 years within this period to be retained in the sample. His/her health status will be assessed by the mean number of yearly chronic diseases at baseline (the 2 years before labour market entry), and three more times (follow-up periods) after the end of the working conditions observation period.

Source: Author. 
Table II: Base sample description $\left(t_{7}\right)$

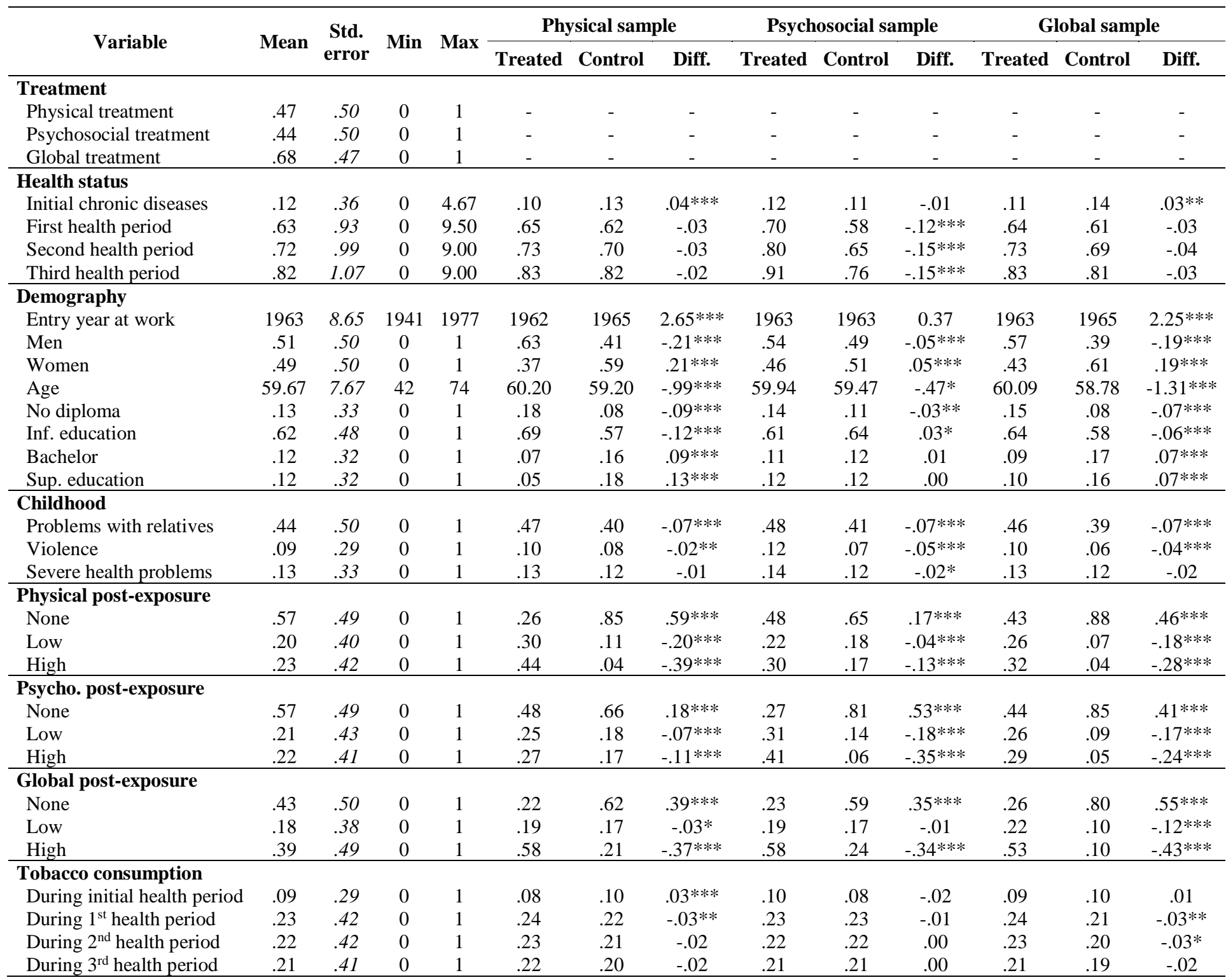

Interpretation: ***: difference significant at the 1\% level, **: difference significant at the 5\% level, *: difference significant at the 10\% level. Standard errors in italics. The average number of chronic diseases in the whole sample before labour market entry is 0.12 . In the future physically treated population, this number is 0.10 (which is significantly lower than for the future control group, i.e., 0.13 at the 1\% level). Such a difference at baseline in health statuses between future treated and control groups does not exist in the psychosocial sample.

Field: Population aged $42-74$ in 2006 and present from $t_{1}$ to $t_{9} .7^{\text {th }}$ threshold. Unmatched sample.

Source: Health and Professional Route survey (Sip), wave 2006. 
Table III: Matched sample description $\left(t_{7}\right)$

\begin{tabular}{lccccccccc}
\hline \multirow{2}{*}{ Variable } & \multicolumn{3}{c}{ Physical sample } & \multicolumn{2}{c}{ Psychosocial sample } & \multicolumn{3}{c}{ Global sample } \\
\cline { 2 - 10 } & Treated & Control & Diff. & Treated & Control & Diff. & Treated & Control & Diff. \\
\hline Health status & & & & & & & & & \\
Initial chronic diseases & .08 & .10 & .02 & .10 & .10 & -.00 & .09 & .12 & .02 \\
First health period & .63 & .55 & $-.07 * *$ & .68 & .54 & $-.13^{* * *}$ & .63 & .56 & $-.07 * *$ \\
Second health period & .72 & .63 & $-.09 * * *$ & .78 & .62 & $-.16^{* * *}$ & .72 & .63 & $-.08^{* *}$ \\
Third health period & .82 & .72 & $-.10^{* * *}$ & .89 & .72 & $-.17 * * *$ & .83 & .74 & $-.09^{* *}$ \\
\hline Demography & & & & & & & & & \\
Entry year at work & 1962 & 1962 & .08 & 1963 & 1963 & -.01 & 1963 & 1963 & .04 \\
Men & .63 & .63 & 0 & .54 & .54 & 0 & .56 & .56 & 0 \\
Women & .37 & .37 & 0 & .46 & .46 & 0 & .44 & .44 & 0 \\
Age & 60.02 & 60.31 & .28 & 59.82 & 59.61 & -.21 & 59.59 & 59.64 & .05 \\
No diploma & .15 & .15 & 0 & .13 & .13 & 0 & .11 & .11 & 0 \\
Inf. education & .72 & .72 & 0 & .65 & .65 & 0 & .70 & .70 & 0 \\
Bachelor & .06 & .06 & 0 & .10 & .10 & 0 & .09 & .09 & 0 \\
Sup. education & .05 & .05 & 0 & .11 & .11 & 0 & .10 & .10 & 0 \\
\hline Childhood & & & & & & & & & \\
Problems with relatives & .45 & .45 & 0 & .46 & .46 & 0 & .41 & .41 & 0 \\
Violence & .07 & .07 & 0 & .07 & .07 & 0 & .04 & .04 & 0 \\
Severe health problems & .10 & .10 & 0 & .10 & .10 & 0 & .09 & .09 & 0 \\
\hline
\end{tabular}

Interpretation: ***: difference significant at the $1 \%$ level, **: difference significant at the $5 \%$ level, *: difference significant at the 10\% level. After matching, there is no significant difference between the future treated and control groups in terms of initial mean number of chronic diseases for physical, psychosocial and global samples.

Field: Population aged 42-74 in 2006 and present from $t_{1}$ to $t_{9} .7^{\text {th }}$ threshold. Matched (weighted) sample. Source: Health and Professional Route survey (Sip), wave 2006. 
Table IV: Matched difference-in-differences results ( $t_{5}$ to $\left.t_{9}\right)$, physical treatment

\begin{tabular}{|c|c|c|c|c|c|c|c|c|c|}
\hline \multirow{2}{*}{$\begin{array}{l}\text { Treatment } \\
\text { Sex }\end{array}$} & \multicolumn{2}{|c|}{ Baseline Diff. } & \multicolumn{2}{|c|}{ Follow-up Diff. } & \multicolumn{2}{|c|}{ Diff.-in-Diff. } & \multirow{2}{*}{$\begin{array}{c}\text { Mean chronic } \\
\text { diseases in treat. }\end{array}$} & \multirow{2}{*}{$\begin{array}{c}\mathrm{N} \\
\text { (treat./tot.) }\end{array}$} & \multirow{2}{*}{$\begin{array}{c}\text { \% matched } \\
\text { (treat./contr.) }\end{array}$} \\
\hline & Coeff. & Std. Err. & Coeff. & Std. Err. & Coeff. & Std. Err. & & & \\
\hline \multicolumn{10}{|c|}{$t_{5}:$ being exposed to at least 12 years of single exposures or 6 years of multiple exposures } \\
\hline \multicolumn{9}{|c|}{ 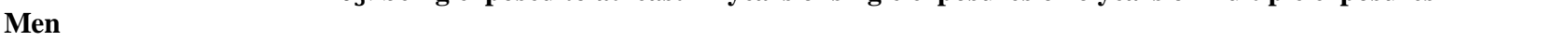 } & \multirow{7}{*}{$90 \% / 88 \%$} \\
\hline First health period & & & .012 & .069 & .036 & .065 & .488 & \multirow{3}{*}{$1908 / 3212$} & \\
\hline Second health period & -.024 & .020 & .012 & .050 & .036 & .068 & .500 & & \\
\hline $\begin{array}{l}\text { Third health period } \\
\text { Women }\end{array}$ & & & .024 & .066 & .048 & .047 & .562 & & \\
\hline First health period & & & .086 & .056 & $.100 *$ & .052 & .439 & \multirow{3}{*}{$1226 / 3044$} & \\
\hline Second health period & -.014 & .019 & .087 & .058 & $.101 * *$ & .043 & .496 & & \\
\hline Third health period & & & $.097 *$ & .051 & $.111 * *$ & .048 & .522 & & \\
\hline \multicolumn{10}{|c|}{$t_{6}$ : being exposed to at least 14 years of single exposures or 7 years of multiple exposures } \\
\hline Men & & & & & & & & & \multirow{8}{*}{$90 \% / 88 \%$} \\
\hline First health period & & & .016 & .072 & .038 & .070 & .497 & & \\
\hline Second health period & -.022 & .019 & .017 & .074 & .039 & .073 & .561 & $1890 / 3196$ & \\
\hline Third health period & & & .024 & .076 & .046 & .072 & 620 & & \\
\hline Women & & & & & & & & & \\
\hline First health period & & & $.134 * * *$ & .055 & $.148 * *$ & .058 & .597 & & \\
\hline Second health period & -.014 & .020 & $.142 * *$ & .060 & $.156^{* * * *}$ & .053 & .653 & $1162 / 3036$ & \\
\hline Third health period & & & $.155^{* *}$ & .067 & $.169 * *$ & .066 & .762 & & \\
\hline \multicolumn{10}{|c|}{$t_{7}$ : being exposed to at least 16 years of single exposures or 8 years of multiple exposures } \\
\hline Men & & & & & & & & & \multirow{8}{*}{$91 \% / 88 \%$} \\
\hline First health period & & & .024 & .075 & .047 & .074 & .607 & & \\
\hline Second health period & -.023 & .017 & .032 & .076 & .055 & .075 & .681 & $1890 / 3226$ & \\
\hline Third health period & & & .066 & .078 & .089 & .077 & .815 & & \\
\hline Women & & & & & & & & & \\
\hline First health period & & & $.178 * * *$ & .068 & $.185 * * *$ & .064 & .769 & & \\
\hline Second health period & -.007 & .018 & $.192 * * *$ & .073 & $.199 * * *$ & .069 & .862 & $1128 / 3042$ & \\
\hline Third health period & & & $.196 * *$ & .081 & $.203 * * *$ & .076 & .959 & & \\
\hline \multicolumn{10}{|c|}{$t_{8}$ : being exposed to at least 18 years of single exposures or 9 years of multiple exposures } \\
\hline Men & & & & & & & & & \multirow{7}{*}{$92 \% / 87 \%$} \\
\hline First health period & & & .063 & .069 & $.076^{*}$ & .052 & .736 & & \\
\hline Second health period & -.013 & .017 & .84 & .070 & $.097 * *$ & .054 & .833 & $1820 / 3224$ & \\
\hline $\begin{array}{l}\text { Third health period } \\
\text { Women }\end{array}$ & & & .87 & .076 & $.100 * *$ & .055 & .946 & & \\
\hline First health period & & & $.193^{* * *}$ & .072 & $.193 * *$ & .079 & .904 & & \\
\hline Second health period & -.000 & .019 & $.210 * * *$ & .078 & $.210 * * *$ & .074 & .970 & $1064 / 3022$ & \\
\hline Third health period & & & $.221 * *$ & .083 & $.221 * * *$ & .068 & 1.044 & & \\
\hline \multicolumn{10}{|c|}{$t_{9}$ : being exposed to at least 20 years of single exposures or 10 years of multiple exposures } \\
\hline Men & & & & & & & & & \multirow{8}{*}{$92 \% / 86 \%$} \\
\hline First health period & & & .80 & .064 & $.087 * *$ & .051 & .764 & & \\
\hline Second health period & -.007 & .016 & $.110 *$ & .066 & $.117 * *$ & .060 & .871 & $1694 / 3232$ & \\
\hline Third health period & & & $.113 *$ & .070 & $.120 * * *$ & .060 & .986 & & \\
\hline Women & & & & & & & & & \\
\hline First health period & & & $.225^{* * *}$ & .075 & $.228 * * *$ & .082 & .909 & & \\
\hline Second health period & -.003 & .019 & $.229 * * *$ & .086 & $.232 * * *$ & .077 & .961 & $970 / 2976$ & \\
\hline Third health period & & & $.246 * * *$ & .081 & $.249 * * *$ & .070 & 1.045 & & \\
\hline
\end{tabular}

Interpretation: ***: significant at the 1\% level, **: significant at the 5\% level, *: significant at the $10 \%$ level. Standard errors in italics. The baseline and follow-up columns show the results for the first differences between the treated and control groups, respectively, before and after the treatment. The diff.-in-diff. column shows the results for the second differences (i.e., the difference between follow-up and baseline differences). The mean chronic diseases column indicates the mean number of chronic diseases of the treated population in the health period considered. The $N$ column gives the sample sizes for, respectively, the treated and total populations. The last column denotes the percentage of the initial sample that found a match for, respectively, the treated and control groups.

Field: Population aged 42-74 in 2006 and present from $t_{1}$ to $t_{9}$. Matched (weighted) sample.

Source: Health and Professional Route survey (Sip), wave 2006. 
Table V: Matched difference-in-differences results $\left(\boldsymbol{t}_{\mathbf{5}}\right.$ to $\left.\boldsymbol{t}_{\mathbf{9}}\right)$, psychosocial treatment

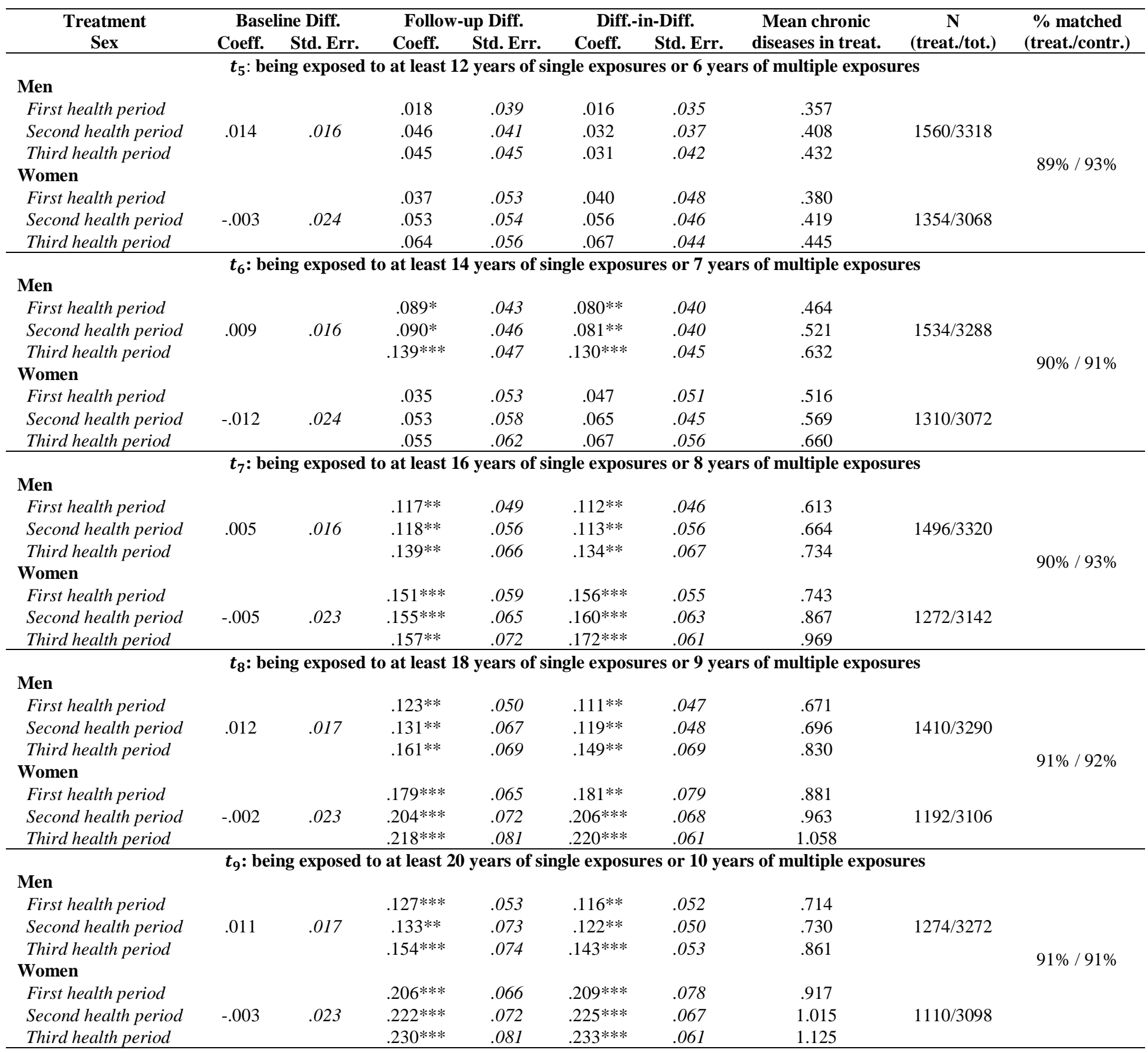

Interpretation: ***: significant at the 1\% level, **: significant at the 5\% level, *: significant at the 10\% level. Standard errors in italics. The baseline and follow-up columns show the results for the first differences between the treated and control groups, respectively, before and after the treatment. The diff.-in-diff. column shows the results for the second differences (i.e., the difference between follow-up and baseline differences). The mean chronic diseases column indicates the mean number of chronic diseases of the treated population in the health period considered. The $N$ column gives the sample sizes for, respectively, the treated and total populations. The last column denotes the percentage of the initial sample that found a match for, respectively, the treated and control groups.

Field: Population aged $42-74$ in 2006 and present from $t_{1}$ to $t_{9}$. Matched (weighted) sample.

Source: Health and Professional Route survey (Sip), wave 2006. 
Table VI: Matched difference-in-differences results ( $\boldsymbol{t}_{\mathbf{5}}$ to $\left.\boldsymbol{t}_{\mathbf{9}}\right)$, global treatment

\begin{tabular}{|c|c|c|c|c|c|c|c|c|c|}
\hline \multirow{2}{*}{$\begin{array}{l}\text { Treatment } \\
\text { Sex }\end{array}$} & \multicolumn{2}{|c|}{ Baseline Diff. } & \multicolumn{2}{|c|}{ Follow-up Diff. } & \multicolumn{2}{|c|}{ Diff.-in-Diff. } & \multirow{2}{*}{$\begin{array}{c}\text { Mean chronic } \\
\text { diseases in treat. }\end{array}$} & \multirow{2}{*}{$\begin{array}{c}\mathbf{N} \\
\text { (treat./tot.) }\end{array}$} & \multirow{2}{*}{$\begin{array}{c}\text { \% matched } \\
\text { (treat./contr.) }\end{array}$} \\
\hline & Coeff. & Std. Err. & Coeff. & Std. Err. & Coeff. & Std. Err. & & & \\
\hline \multicolumn{10}{|c|}{$t_{5}:$ being exposed to at least 12 years of single exposures or 6 years of multiple exposures } \\
\hline \multicolumn{9}{|c|}{ ( } & \multirow{8}{*}{$82 \% / 94 \%$} \\
\hline First health period & & & -.003 & .067 & .023 & .066 & .391 & \multirow{4}{*}{$2256 / 3002$} & \\
\hline Second health period & -.026 & .022 & -.003 & .070 & .023 & .069 & .401 & & \\
\hline Third health period & & & .017 & .053 & .043 & .049 & .434 & & \\
\hline Women & & & & & & & & & \\
\hline First health period & & & .024 & .056 & .025 & .051 & .386 & \multirow{3}{*}{$1850 / 3018$} & \\
\hline Second health period & -.001 & .023 & .032 & .054 & .033 & .047 & .438 & & \\
\hline Third health period & & & .034 & .056 & .035 & .049 & .473 & & \\
\hline \multicolumn{10}{|c|}{$t_{6}$ : being exposed to at least 14 years of single exposures or 7 years of multiple exposures } \\
\hline Men & & & & & & & & & \multirow{8}{*}{$80 \% / 94 \%$} \\
\hline First health period & & & -.019 & .073 & .013 & .073 & .431 & & \\
\hline Second health period & -.032 & .021 & -.010 & .074 & .022 & .075 & .491 & $2192 / 2962$ & \\
\hline Third health period & & & .025 & .076 & .057 & .076 & .589 & & \\
\hline Women & & & & & & & & & \\
\hline First health period & & & .067 & .057 & .076 & .054 & .527 & & \\
\hline Second health period & -.009 & .021 & .078 & .054 & .087 & .050 & .586 & $1734 / 2978$ & \\
\hline Third health period & & & .089 & .063 & $.098^{*}$ & .056 & .688 & & \\
\hline \multicolumn{10}{|c|}{$t_{7}$ : being exposed to at least 16 years of single exposures or 8 years of multiple exposures } \\
\hline Men & & & & & & & & & \multirow{8}{*}{$81 \% / 94 \%$} \\
\hline First health period & & & .018 & .038 & .049 & .067 & .588 & & \\
\hline Second health period & -.031 & .020 & .038 & .070 & .069 & .069 & .671 & $2160 / 2978$ & \\
\hline Third health period & & & .049 & .074 & .80 & .073 & .804 & & \\
\hline Women & & & & & & & & & \\
\hline First health period & & & $.143 * * *$ & .071 & $.148 * * *$ & .067 & .740 & & \\
\hline Second health period & -.005 & .020 & $.157 * * *$ & .058 & $.162 * * *$ & .054 & .859 & $1710 / 3010$ & \\
\hline Third health period & & & $.167 * * *$ & .063 & $.173 * * *$ & .059 & .972 & & \\
\hline \multicolumn{10}{|c|}{$t_{8}$ : being exposed to at least 18 years of single exposures or 9 years of multiple exposures } \\
\hline Men & & & & & & & & & \multirow{7}{*}{$82 \% / 94 \%$} \\
\hline First health period & & & .058 & .066 & .080 & .064 & .703 & & \\
\hline Second health period & -.022 & .019 & .065 & .071 & .087 & .069 & .772 & $2126 / 3024$ & \\
\hline $\begin{array}{l}\text { Third health period } \\
\text { Women }\end{array}$ & & & .114 & .074 & $.136 *$ & .073 & .934 & & \\
\hline First health period & & & $.138 *$ & .083 & $.139 *$ & .081 & .840 & & \\
\hline Second health period & -.001 & .019 & $.170^{* *}$ & .071 & $.171 * *$ & .068 & .936 & $1652 / 3034$ & \\
\hline Third health period & & & $.180 * * *$ & .064 & $.181 * * *$ & .061 & 1.044 & & \\
\hline \multicolumn{10}{|c|}{$t_{9}$ : being exposed to at least 20 years of single exposures or 10 years of multiple exposures } \\
\hline Men & & & & & & & & & \multirow{8}{*}{$86 \% / 93 \%$} \\
\hline First health period & & & .097 & .063 & $.100 *$ & .055 & .724 & & \\
\hline Second health period & -.003 & .017 & .099 & .067 & $.102 *$ & .056 & .777 & $2146 / 3172$ & \\
\hline Third health period & & & $.113 *$ & .071 & $.116^{*}$ & .068 & .925 & & \\
\hline Women & & & & & & & & & \\
\hline First health period & & & $.191 * *$ & .077 & $.190 * *$ & .075 & .885 & & \\
\hline Second health period & .001 & .019 & $.206 * * *$ & .061 & $.205 * * *$ & .058 & .992 & $1586 / 3072$ & \\
\hline Third health period & & & $.210 * * *$ & .067 & $.209 * * *$ & .064 & 1.095 & & \\
\hline
\end{tabular}

Interpretation: ***: significant at the 1\% level, **: significant at the 5\% level, *: significant at the 10\% level. Standard errors in italics. The baseline and follow-up columns show the results for the first differences between the treated and control groups, respectively, before and after the treatment. The diff.-in-diff. column shows the results for the second differences (i.e., the difference between follow-up and baseline differences). The mean chronic diseases column indicates the mean number of chronic diseases of the treated population in the health period considered. The $N$ column gives the sample sizes for, respectively, the treated and total populations. The last column denotes the percentage of the initial sample that found a match for, respectively, the treated and control groups.

Field: Population aged 42-74 in 2006 and present from $t_{1}$ to $t_{9}$. Matched (weighted) sample.

Source: Health and Professional Route survey (Sip), wave 2006. 


\section{APPENDIX 1: DETAILED DESCRIPTION OF THE PARAMETERS}

The nine thresholds are designed according to increasing levels of exposures to detrimental working conditions: a 2-year step for single exposures from one threshold to another. Polyexposure durations are half that of single ones, based on the requirements of the 2015 French law requiring that past professional exposures to detrimental working conditions be taken into account in pension calculations (in which simultaneous strains count twice as much as single exposures - Sirugue et al., 2015). The durations of the observation periods for working conditions are set arbitrarily to allow some time for reaching the treatment thresholds: it represents three halves of the maximum duration of exposure needed to be treated, i.e., three halves of the single exposure threshold). The minimum duration at work during the observation period is set as the minimum exposure threshold to be treated, i.e., it equals the poly-exposure threshold. The length of observation periods for chronic diseases is set to two years in order to avoid choosing overly specific singletons while preserving sample sizes.

The estimations are performed on these nine thresholds using the same sample of individuals: I keep only individuals existing in all nine of them for comparison purposes. The sample is thus based on the most demanding threshold, $t_{9}$. This means that, in this setup, individuals must be observed for a minimal duration of 38 years ( 2 years before labour market entry for baseline health status, plus 30 years of observation - including a minimum of 10 years in the labour market - and 6 years of follow-up health status periods - see Figure 1). In other words, with the date of the survey being 2006, this means that the retained individuals $(6,700)$ are those who entered the labour market before 1970 (and existing in the dataset before 1968), inducing heavily reduced sample sizes in comparison to the 13,000 starting individuals. 


\section{APPENDIX 2: CONTROLS FOR POST-TREATMENT EXPOSURES}

Table VII: Results with and without controlling for post-treatment exposures - Physical, psychosocial and global treatments $\left(t_{7}\right)$ - Matched samples

\begin{tabular}{|c|c|c|c|c|}
\hline \multirow{2}{*}{$\begin{array}{l}\text { Treatment } \\
\text { Sex }\end{array}$} & \multicolumn{2}{|c|}{$\begin{array}{c}\text { Diff.-in-Diff. } \\
\text { (with post-exposure control) }\end{array}$} & \multicolumn{2}{|c|}{$\begin{array}{c}\text { Diff.-in-Diff. } \\
\text { (without post-exposure control) }\end{array}$} \\
\hline & Coeff. & Std. Err. & Coeff. & Std. Err. \\
\hline \multicolumn{5}{|c|}{$t_{7}:$ being exposed to at least 16 years of single exposures or 8 years of multiple exposures } \\
\hline \multicolumn{5}{|l|}{ Men } \\
\hline First health period & .047 & .074 & .024 & .044 \\
\hline Second health period & .055 & .075 & .035 & .046 \\
\hline Third health period & .089 & .077 & .046 & .048 \\
\hline \multicolumn{5}{|l|}{ Women } \\
\hline First health period & $.185^{* * * *}$ & .064 & $.194 * * *$ & .058 \\
\hline Second health period & $.199 * * *$ & .069 & $.211 * * *$ & .062 \\
\hline Third health period & $.203 * * *$ & .076 & $.219 * * *$ & .067 \\
\hline \multicolumn{5}{|c|}{$t_{7}$ : being exposed to at least 16 years of single exposures or 8 years of multiple exposures } \\
\hline & & cial treatm & & \\
\hline \multicolumn{5}{|c|}{ 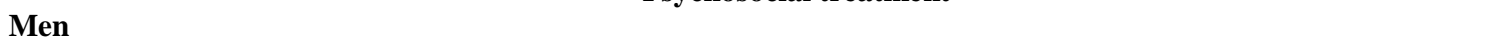 } \\
\hline First health period & $.112 * *$ & .046 & $.109 * * *$ & .040 \\
\hline Second health period & $.113 * *$ & .056 & $.135 * * *$ & .043 \\
\hline Third health period & $.134 * *$ & .067 & $.170 * * *$ & .046 \\
\hline \multicolumn{5}{|l|}{ Women } \\
\hline First health period & $.156^{* * *}$ & .055 & $.170 * * *$ & .061 \\
\hline Second health period & $.160 * * *$ & .063 & $.171 * * *$ & .050 \\
\hline Third health period & $.172 * * *$ & .061 & $.179 * * *$ & .055 \\
\hline
\end{tabular}

Third health period $\boldsymbol{t}_{\mathbf{7}}$ : being exposed to at least 16 years of single exposures or 8 years of multiple exposures

Global treatment

Men

$\begin{array}{lllll}\text { First health period } & .049 & .067 & .040 & .049 \\ \text { Second health period } & .069 & .069 & .062 & .051 \\ \text { Third health period } & .080 & .073 & .090^{*} & .053 \\ \text { Women } & & & & .129 * * \\ \text { First health period } & .148^{* * *} & .067 & .152 * * * & .061 \\ \text { Second health period } & .162 * * * & .054 & .156^{* * *} & .050 \\ \text { Third health period } & .173^{* * *} & .059 & .054\end{array}$

Interpretation: ***: difference significant at the 1\% level, **: difference significant at the 5\% level, *: difference significant at the $10 \%$ level. Standard errors in italics. In physically treated women and when controlling for the possibility of post-treatment exposures, the fact of being exposed increases the mean number of chronic diseases by .185, .199 and .203 for, respectively, the first, second and third health periods. For the same population but without controlling for potential post-treatment exposures, it increases this number by, respectively, .194, .211 and .219. No significant difference between the two specifications can be observed (the standard errors crossing each other).

Field: Population aged 42-74 in 2006 and present from $t_{1}$ to $t_{9} .7^{\text {th }}$ threshold. Matched (weighted) sample.

Source: Health and Professional Route survey (Sip), wave 2006. 


\section{APPENDIX 3: COMMON TREND ASSUMPTION TEST}

Figure 2: Common trend assumption test - Physical sample $\left(t_{7}\right)$
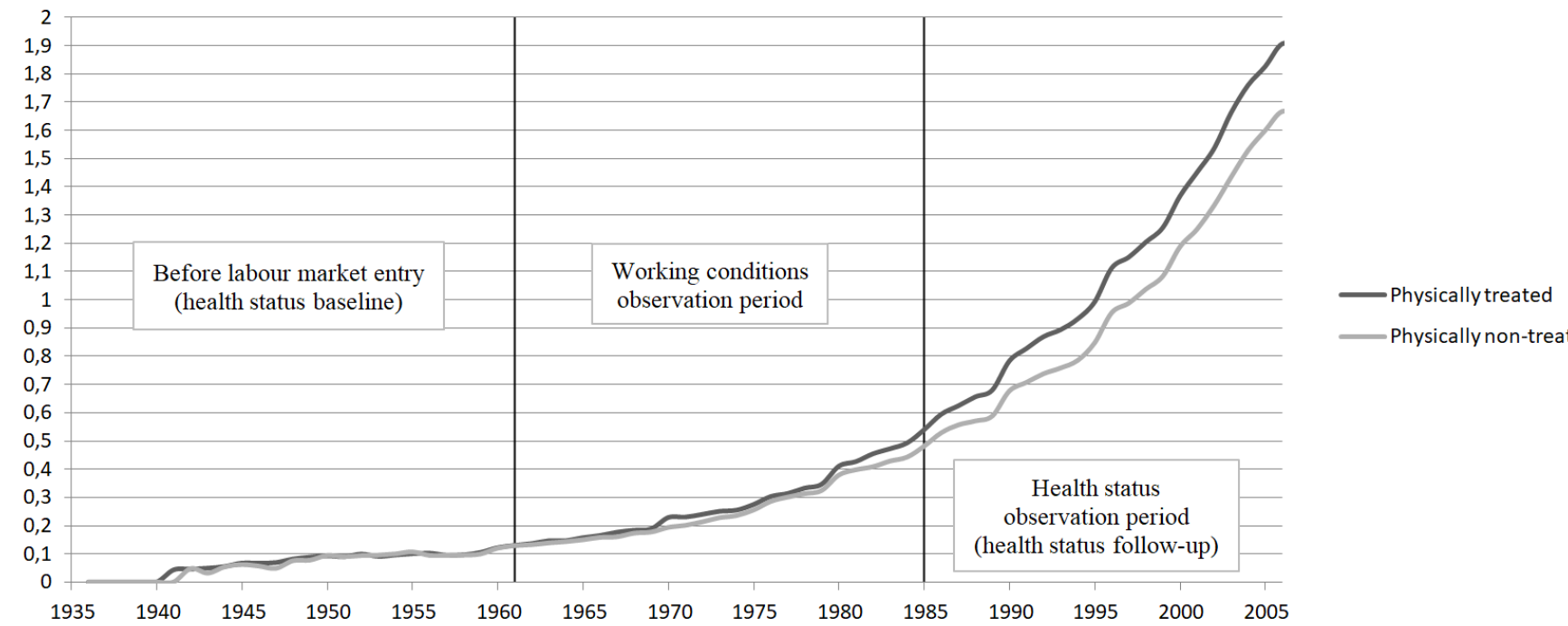

Field: Population aged 42-74 in 2006 and present from $t_{1}$ to $t_{9} .7^{\text {th }}$ threshold. Matched sample. Source: Health and Professional Route survey (Sip), wave 2006.

Figure 3: Common trend assumption test - Psychosocial sample $\left(t_{7}\right)$

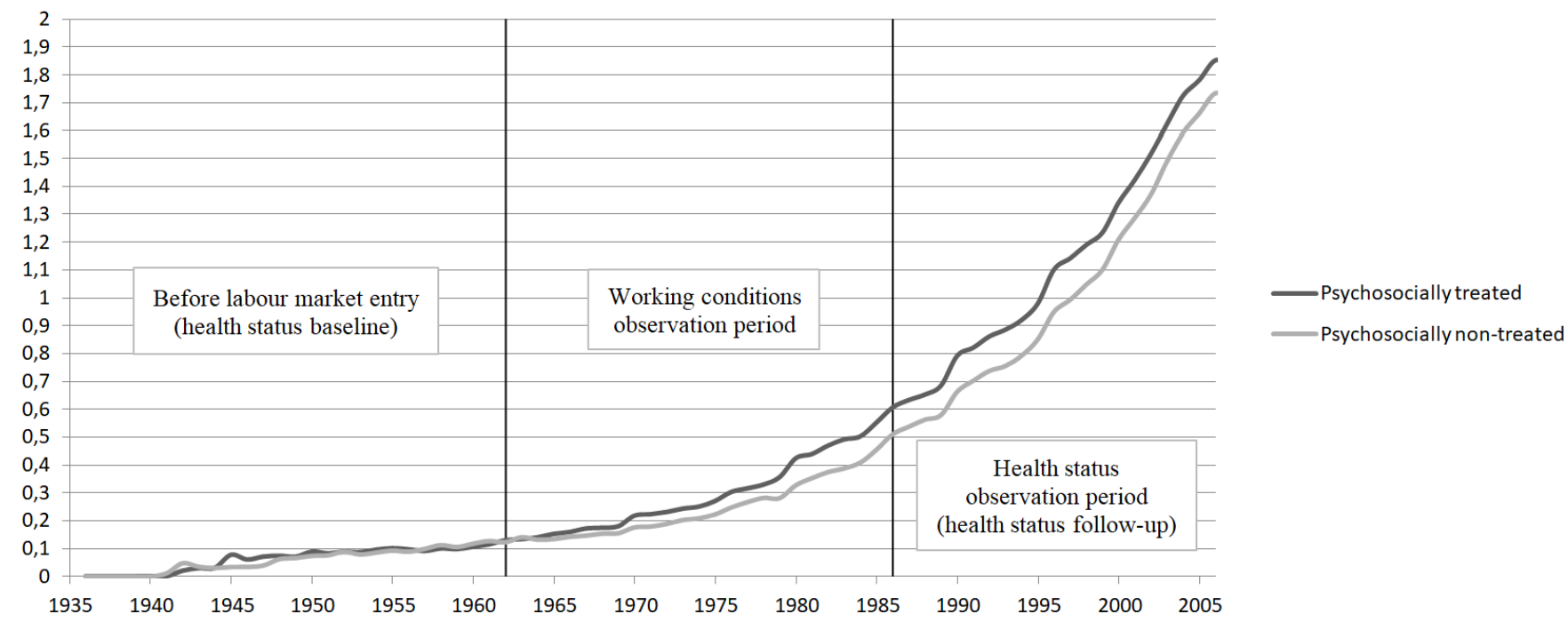

Field: Population aged 42-74 in 2006 and present from $t_{1}$ to $t_{9} .7^{\text {th }}$ threshold. Matched sample. Source: Health and Professional Route survey (Sip), wave 2006. 
Figure 4: Common trend assumption test - Global sample $\left(t_{7}\right)$

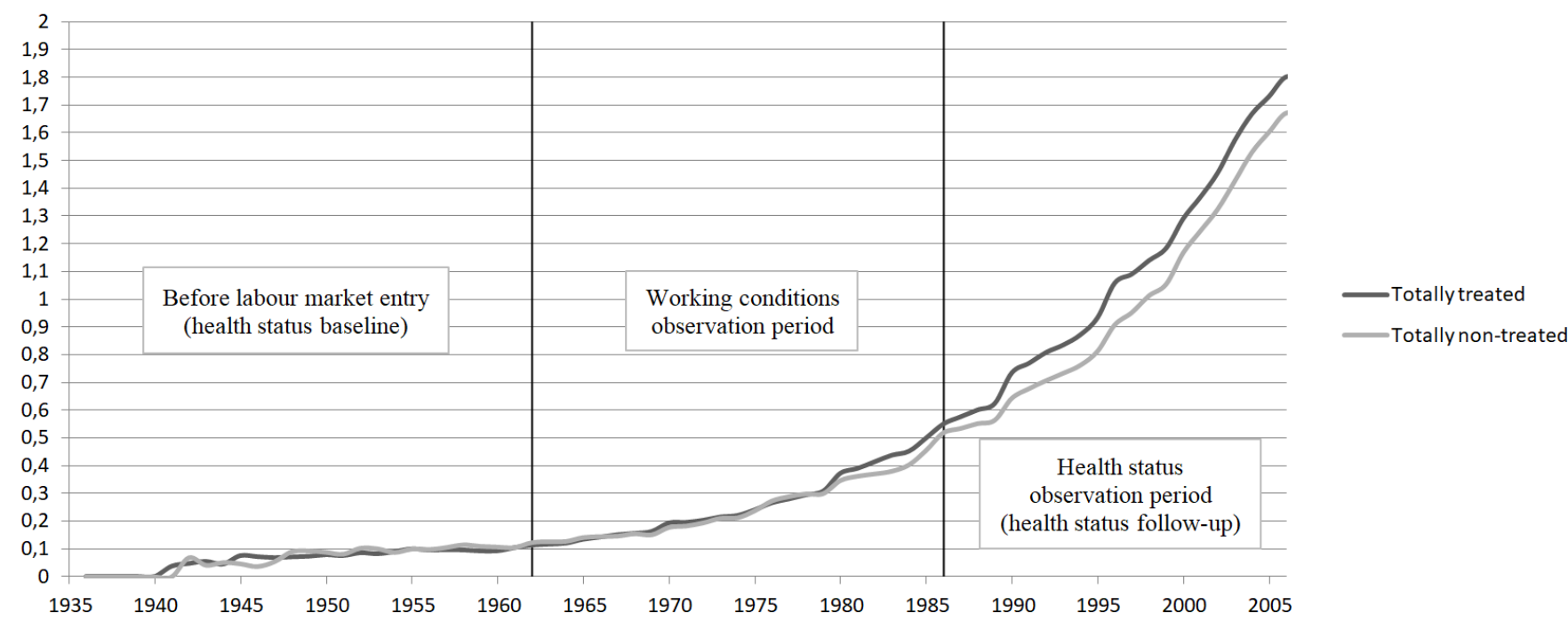

Field: Population aged 42-74 in 2006 and present from $t_{1}$ to $t_{9} .7^{\text {th }}$ threshold. Matched sample. Source: Health and Professional Route survey (Sip), wave 2006. 


\section{APPENDIX 4: SPECIFICATION TEST}

Table VIII: Specification test - Matched Diff.-in-Diff. vs. Matched Ordinary Least Squares (OLS) - Physical, psychosocial and global treatments $\left(t_{7}\right)$ - Matched samples

\begin{tabular}{|c|c|c|c|c|}
\hline \multirow{2}{*}{$\begin{array}{l}\text { Treatment } \\
\text { Sex }\end{array}$} & \multicolumn{2}{|c|}{ Matched Diff.-in-Diff. } & \multicolumn{2}{|c|}{ Matched OLS } \\
\hline & Coeff. & Std. Err. & Coeff. & Std. Err. \\
\hline \multicolumn{5}{|c|}{$t_{7}$ : being exposed to at least 16 years of single exposures or 8 years of multiple exposures } \\
\hline \multicolumn{5}{|c|}{ (20) } \\
\hline First health period & .047 & .074 & .037 & .075 \\
\hline Second health period & .055 & .075 & .046 & .076 \\
\hline Third health period & .089 & .077 & .079 & .078 \\
\hline \multicolumn{5}{|l|}{ Women } \\
\hline First health period & $.185 * * *$ & .064 & $.193 * * *$ & .068 \\
\hline Second health period & $.199 * * *$ & .069 & $.207 * * *$ & .073 \\
\hline Third health period & $.203 * * *$ & .076 & $.209 * * *$ & .080 \\
\hline \multicolumn{5}{|c|}{$t_{7}:$ being exposed to at least 16 years of single exposures or 8 years of multiple exposures } \\
\hline \multicolumn{5}{|c|}{ (2) } \\
\hline First health period & $.112 * *$ & .046 & $.126 * * *$ & .049 \\
\hline Second health period & $.113 * *$ & .056 & $.129 * * *$ & .057 \\
\hline Third health period & $.134 * *$ & .067 & $.149 * * *$ & .066 \\
\hline \multicolumn{5}{|l|}{ Women } \\
\hline First health period & $.156 * * *$ & .055 & $.162 * * *$ & .059 \\
\hline Second health period & $.160 * * *$ & .063 & $.166 * * *$ & .072 \\
\hline Third health period & $.172 * * *$ & .061 & $.179 * * *$ & .064 \\
\hline \multicolumn{5}{|c|}{$\begin{array}{c}t_{7} \text { : being exposed to at least } 16 \text { years of single exposures or } 8 \text { years of multiple exposures } \\
\text { Global treatment }\end{array}$} \\
\hline \multicolumn{5}{|c|}{ 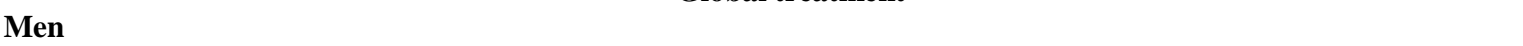 } \\
\hline First health period & .049 & .067 & .031 & .068 \\
\hline Second health period & .069 & .069 & .054 & .070 \\
\hline Third health period & .080 & .073 & .098 & .073 \\
\hline \multicolumn{5}{|l|}{ Women } \\
\hline First health period & $.148 * * *$ & .067 & $.146 * * *$ & .040 \\
\hline Second health period & $.162 * * *$ & .054 & $.168 * * *$ & .058 \\
\hline Third health period & $.173 * * *$ & .059 & $.176 * * *$ & .063 \\
\hline
\end{tabular}

Interpretation: ***: difference significant at the 1\% level, **: difference significant at the $5 \%$ level, *: difference significant at the $10 \%$ level. Standard errors in italics.

Field: Population aged 42-74 in 2006 and present from $t_{1}$ to $t_{9} .7^{\text {th }}$ threshold. Matched (weighted) sample.

Source: Health and Professional Route survey (Sip), wave 2006. 


\section{APPENDIX 5: THRESHOLD TEST}

Table IX: Thresholds tests - Normal treatment vs. Single exposures only vs. Poly-exposures only - Physical, psychosocial and global treatments $\left(t_{7}\right)$ - Matched samples

\begin{tabular}{|c|c|c|c|c|c|c|}
\hline \multirow{2}{*}{$\begin{array}{l}\text { Treatment } \\
\quad \text { Sex }\end{array}$} & \multicolumn{2}{|c|}{$\begin{array}{l}\text { Normal Diff.-in-Diff. } \\
\text { (16 single or } 8 \text { poly) }\end{array}$} & \multicolumn{2}{|c|}{$\begin{array}{l}\text { Single Diff.-in-Diff. } \\
\text { (16 single) }\end{array}$} & \multicolumn{2}{|c|}{$\begin{array}{l}\text { Poly Diff.-in-Diff. } \\
\text { (8 poly) }\end{array}$} \\
\hline & Coeff. & Std. Err. & Coeff. & Std. Err. & Coeff. & Std. Err. \\
\hline \multicolumn{7}{|c|}{$t_{7}$ : being exposed to at least 16 years of single exposures or 8 years of multiple exposures } \\
\hline \multicolumn{7}{|c|}{ 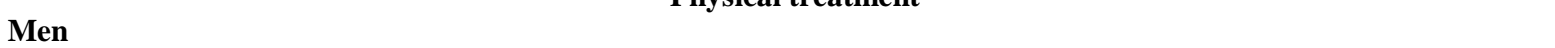 } \\
\hline First health period & .047 & .074 & .010 & .060 & .104 & .074 \\
\hline Second health period & .055 & .075 & .015 & .067 & .107 & .078 \\
\hline Third health period & .089 & .077 & .017 & .068 & .110 & .075 \\
\hline \multicolumn{7}{|l|}{ Women } \\
\hline First health period & $.185^{* * *}$ & .064 & $.109 *$ & .064 & $.234 * * *$ & .097 \\
\hline Second health period & $.199 * * *$ & .069 & $.129 * *$ & .072 & $.239 * * *$ & .085 \\
\hline Third health period & $.203 * * *$ & .076 & $.130 * *$ & .076 & $.242 * * *$ & .074 \\
\hline \multicolumn{7}{|c|}{$t_{7}$ : being exposed to at least 16 years of single exposures or 8 years of multiple exposures } \\
\hline & & Psychosoci & atment & & & \\
\hline \multicolumn{7}{|l|}{ Men } \\
\hline First health period & $.112 * *$ & .046 & $.094 *$ & .054 & $.152 * *$ & .061 \\
\hline Second health period & $.113^{* *}$ & .056 & $.097 *$ & .057 & $.158 * * *$ & .046 \\
\hline Third health period & $.134 * *$ & .067 & $.127 * *$ & .059 & $.159 * * *$ & .073 \\
\hline \multicolumn{7}{|l|}{ Women } \\
\hline First health period & $.156 * * *$ & .055 & $.111 * *$ & .060 & $.210 * * *$ & .074 \\
\hline Second health period & $.160 * * *$ & .063 & $.115^{* *}$ & .068 & $.213 * * *$ & .060 \\
\hline Third health period & $.172 * * *$ & .061 & $.120 * *$ & .076 & $.223 * * *$ & .065 \\
\hline \multirow{2}{*}{\multicolumn{7}{|c|}{$\begin{array}{c}t_{7}: \text { being exposed to at least } 16 \text { years of single exposures or } 8 \text { years of multiple exposures } \\
\text { Global treatment }\end{array}$}} \\
\hline & & & & & & \\
\hline \multicolumn{7}{|l|}{ Men } \\
\hline First health period & .049 & .067 & .031 & .049 & .110 & .076 \\
\hline Second health period & .069 & .069 & .064 & .051 & .117 & .075 \\
\hline Third health period & .080 & .073 & .070 & .054 & .127 & .083 \\
\hline \multicolumn{7}{|l|}{ Women } \\
\hline First health period & $.148 * * *$ & .067 & $.108 *$ & .060 & $.223 * * *$ & .067 \\
\hline Second health period & $.162 * * *$ & .054 & $.130 * *$ & .062 & $.225^{* * *}$ & .054 \\
\hline Third health period & $.173 * * *$ & .059 & $.133 * *$ & .063 & $.243^{* * * *}$ & .059 \\
\hline
\end{tabular}

Interpretation: ***: difference significant at the 1\% level, **: difference significant at the 5\% level, *: difference significant at the $10 \%$ level. Standard errors in italics. In physically treated women, the fact of being exposed to at least 16 years of single exposures only increases the mean number of chronic diseases by .109, .129 and .130 for, respectively, the first, second and third health periods. Being exposed to at least 8 years of simultaneous exposures only increases this number by, respectively, .234, .239 and .242. Even though the years of simultaneous exposures increase the number of chronic diseases more in the treated group than do the years in single exposure, no significant difference between the two can be observed (the standard errors crossing each other).

Field: Population aged 42-74 in 2006 and present from $t_{1}$ to $t_{9} .7^{\text {th }}$ threshold. Matched (weighted) sample.

Source: Health and Professional Route survey (Sip), wave 2006. 


\section{APPENDIX 6: EXPLORATORY ANALYSIS ON HEALTH HABITS}

Table X: Wage and risky behaviours in 2006 - Unmatched and matched samples

\begin{tabular}{|c|c|c|c|c|c|c|c|c|c|c|c|c|c|}
\hline \multirow{2}{*}{ Variable } & \multirow{2}{*}{ Mean } & \multirow{2}{*}{$\begin{array}{l}\text { Std. } \\
\text { error }\end{array}$} & \multirow{2}{*}{ Min } & \multirow{2}{*}{ Max } & \multicolumn{3}{|c|}{ Physical sample } & \multicolumn{3}{|c|}{ Psychosocial sample } & \multicolumn{3}{|c|}{ Global sample } \\
\hline & & & & & Treated & Control & Diff. & Treated & Control & Diff. & Treated & Control & Diff. \\
\hline \multicolumn{14}{|l|}{ Unmatched } \\
\hline Wage (monthly) & 1639 & 1546 & 0 & 20000 & 1482 & 1740 & $258 * * *$ & 1580 & 1675 & 94 & 1549 & 1773 & $224 * *$ \\
\hline Alcohol & .22 & .41 & 0 & 1 & .23 & .21 & $-.03^{*}$ & .22 & .23 & -.01 & .23 & .19 & $-.04 * *$ \\
\hline Overweight & .58 & .49 & 0 & 1 & .63 & .53 & $-.10 * * *$ & .57 & .58 & .01 & .60 & .54 & $-.06^{* * *}$ \\
\hline Tobacco & .16 & .37 & 0 & 1 & .16 & .16 & .00 & .16 & .16 & -.01 & .16 & .16 & -.01 \\
\hline Physical activities & .27 & .42 & 0 & 1 & .27 & .28 & .01 & .29 & .30 & .01 & .29 & .31 & .02 \\
\hline Alcohol & .25 & .40 & 0 & 1 & .24 & .25 & .02 & .22 & .24 & .02 & .24 & .25 & .02 \\
\hline Overweight & .61 & .46 & 0 & 1 & .63 & .60 & -.02 & .58 & .59 & .01 & .59 & .58 & -.00 \\
\hline Tobacco & .16 & .35 & 0 & 1 & .16 & .17 & .01 & .17 & .16 & -.01 & .16 & .16 & -.01 \\
\hline
\end{tabular}

Interpretation: ***: difference significant at the 1\% level, **: difference significant at the $5 \%$ level, *: difference significant at the $10 \%$ level. Standard errors in italics. $30 \%$ of the general sample (unmatched) had daily physical activities in 2006 when only $27 \%$ of the physically treated sample did (vs. 32\% of the physical control group). This difference of 6 percentage points is significant at the 1\% level. After matching, no significant difference between physically treated and control groups remain concerning daily physical activities.

Field: Population aged $42-74$ in 2006 and present from $t_{1}$ to $t_{9} .7^{\text {th }}$ threshold. Unmatched and matched (weighted) samples.

Source: Health and Professional Route survey (Sip), wave 2006. 


\section{APPENDIX 7: EXPLORATORY ANALYSIS ON GENDER-GAPS}

Table XI: Gender and working conditions typologies, per activity sector in 2006

\begin{tabular}{|c|c|c|c|c|c|c|}
\hline \multirow{2}{*}{ Variable } & \multicolumn{6}{|c|}{$\begin{array}{l}\text { Activity sector } \\
\end{array}$} \\
\hline & Farmer $(\%)$ & Artisan (\%) & Manager (\%) & Intermediate (\%) & Employee (\%) & Blue collar (\%) \\
\hline \multicolumn{7}{|l|}{ Gender } \\
\hline Men & 69.60 & 64.27 & 55.54 & 45.25 & 19.06 & 80.03 \\
\hline Women & 30.40 & 35.73 & 44.46 & 54.75 & 80.94 & 19.97 \\
\hline \multicolumn{7}{|l|}{ Working conditions } \\
\hline Night work & 3.96 & 7.19 & 2.79 & 6.44 & 6.16 & 15.60 \\
\hline Repetitive work & 17.62 & 11.46 & 5.49 & 9.40 & 20.09 & 34.51 \\
\hline Heavy load & 63.88 & 50.56 & 17.75 & 26.09 & 36.24 & 54.59 \\
\hline Hazardous materials & 31.72 & 22.25 & 6.42 & 15.94 & 13.72 & 38.03 \\
\hline Cannot use skills & 7.49 & 4.72 & 7.44 & 9.75 & 16.80 & 17.95 \\
\hline Work under pressure & 19.38 & 28.31 & 44.80 & 33.69 & 22.64 & 24.22 \\
\hline Tensions with public & 4.41 & 11.01 & 13.36 & 15.33 & 12.37 & 4.92 \\
\hline Lack of recognition & 43.61 & 17.98 & 22.91 & 31.67 & 36.94 & 37.19 \\
\hline Cannot conciliate private and work lives & 14.98 & 16.18 & 15.81 & 10.66 & 8.01 & 7.10 \\
\hline Bad relationships with colleagues & 4.41 & 3.15 & 4.48 & 5.23 & 7.52 & 9.23 \\
\hline
\end{tabular}

Interpretation: $30 \%$ of farmers are women, when $70 \%$ are men. In farmers, close to $4 \%$ declared working at night.

Field: General Health and Professional Route survey sample.

Source: Health and Professional Route survey (Sip), wave 2006.

Table XII: Working conditions typology, by gender in 2006

\begin{tabular}{|c|c|c|c|}
\hline \multirow[b]{2}{*}{ Variable } & \multicolumn{2}{|c|}{ Gender } & \multirow{2}{*}{$\begin{array}{c}\text { Difference } \\
\text { Men/Women }\left(\mathrm{Chi}^{2} \text { test }\right)\end{array}$} \\
\hline & Men (\%) & Women (\%) & \\
\hline \multicolumn{4}{|l|}{ Working conditions } \\
\hline Night work & 70.36 & 29.64 & $-40.72 * * *$ \\
\hline Repetitive work & 49.90 & 50.10 & .20 \\
\hline Heavy load & 51.10 & 48.90 & $-2.20 * * *$ \\
\hline Hazardous materials & 61.85 & 38.15 & $-23.70 * * *$ \\
\hline Cannot use skills & 46.29 & 53.71 & 7.42 \\
\hline Work under pressure & 52.25 & 47.75 & $-4.50 * * *$ \\
\hline Tensions with public & 44.02 & 55.98 & $11.96 * * *$ \\
\hline Lack of recognition & 47.16 & 52.84 & 5.68 \\
\hline Cannot conciliate private and work lives & 49.21 & 50.79 & 1.58 \\
\hline Bad relationships with colleagues & 47.83 & 52.17 & 4.34 \\
\hline
\end{tabular}

Interpretation: ***: difference significant at the 1\% level, **: difference significant at the $5 \%$ level, *: difference significant at the $10 \%$ level. $70 \%$ of night workers are men and $30 \%$ are women. The difference in proportions is significant at the $1 \%$ level.

Field: General Health and Professional Route survey sample.

Source: Health and Professional Route survey (Sip), wave 2006. 